\title{
GROUND MOTION MODELS FOR ARIAS INTENSITY, CUMULATIVE ABSOLUTE VELOCITY, PEAK INCREMENTAL GROUND VELOCITY, AND SIGNIFICANT DURATION IN NEW ZEALAND
}

\author{
Zach Bullock ${ }^{1}$ \\ (Submitted October 2018; Reviewed February 2019; Accepted August 2019)
}

\begin{abstract}
This study proposes empirical ground motion models for a variety of non-spectral intensity measures and significant durations in New Zealand. Equations are presented for the prediction of the median and maximum rotated components of Arias intensity, cumulative absolute velocity, cumulative absolute velocity above a 5 $\mathrm{cm} / \mathrm{s}^{2}$ acceleration threshold, peak incremental ground velocity, and the 5\% to $75 \%$ and $5 \%$ to $95 \%$ significant durations. Recent research has highlighted the usefulness of these parameters in both structural and geotechnical engineering. The New Zealand Strong Motion Database provides the database for regression and includes many earthquakes from all regions of New Zealand with the exceptions of Auckland and Northland, Otago and Southland, and Taranaki. The functional forms for the proposed models are selected using cross validation. The possible influence of effects not typically included in ground motion models for these intensity measures is considered, such as hanging wall effects and basin depth effects, as well as altered attenuation in the Taupo Volcanic Zone. The selected functional forms include magnitude and rupture depth scaling, attenuation with distance, and shallow site effects. Finally, the spatial autocorrelation of the models' within-event residuals is considered and recommendations are made for developing correlated maps of intensity predictions stochastically.
\end{abstract}

\section{INTRODUCTION}

\section{Background}

Empirical ground motion models (GMMs) are a fundamental component of any probabilistic seismic hazard analysis (PSHA; [1]). These models yield predictions of the intensity or duration of ground motion as a function of characteristics of a given earthquake scenario, such as moment magnitude and distance to rupture. GMMs are developed by performing regressions on databases of ground motion records from past earthquakes. The target variables in these regressions are measures of intensity or duration of shaking.

Ground motion intensity is quantified in terms of a variety of intensity measures (IMs) and significant durations. IMs fall into two broad categories: peak transient, which reflect some aspect of the strongest portion of shaking (e.g., peak ground acceleration); and evolutionary, which incorporate the amplitude of motion over the entire course of shaking (e.g., cumulative absolute velocity).

Many GMMs have been developed to predict the spectral acceleration $\left(S_{a}\right)$ at a given site in a given earthquake (e.g., [26]). Relatively fewer GMMs have been developed to predict evolutionary IMs and significant durations (e.g., [7-10]). Stafford et al. [11] was developed specifically for predicting an evolutionary IM in New Zealand, and it included foreign records in its regression database to address data availability. Van Houtte et al. [12] produced a model for the 5\% to $75 \%$ significant duration $\left(D_{5-75}\right)$ using a subset of records from the New Zealand Strong Motion Database.

The publication of the New Zealand Strong Motion Database (NZSMD; [13]) presents an opportunity to GMMs for a variety of non-spectral IMs and significant durations for specific application in New Zealand. The metadata in the NZSMD allow for investigation of effects not often incorporated into GMMs for such IMs, such as hanging wall and sediment depth effects. Additionally, the volume and geographic density of records in the NZSMD allow for the development of models for spatial autocorrelation.

\section{Intensity Measures}

This study considers four evolutionary or non-spectral IMs and two measures of significant duration. The median rotated (RotD50) and maximum rotated (RotD100) components of each IM are considered. Arias intensity $\left(I_{A} ;[14]\right)$ is the most widely-used evolutionary IM in geotechnical engineering. Equation 1 provides its definition, where $t_{d}$ is the duration of the record, $a(t)$ is the acceleration time history, and $g$ is the acceleration of gravity.

$$
I_{A}=\frac{\pi}{2 g} \int_{0}^{t_{d}} a(t)^{2} d t
$$

$I_{A}$ can also be formulated in the frequency domain through the application of Parseval's theorem. Previous models for predicting $I_{A}$ have in some cases depended on this formulation $[11,15]$ to guide functional form selection. Other models [8, 10] have calculated $I_{A}$ according to Equation 1 and disregarded the frequency domain. This study will do the latter. The models developed here provide a basis for future research investigating the influence of the minimum and maximum usable frequencies on modelling $I_{A}$ for the NZSMD.

Cumulative absolute velocity (CAV; [16]), as defined by Equation 2, may offer advantages over Arias intensity in certain 
applications [17-20]. Additionally, it generally has smaller model uncertainty, perhaps due to its definition.

$$
C A V=\int_{0}^{t_{d}}|a(t)| d t
$$

Several permutations of $C A V$ with specific applications also exist in the literature. The $C A V$ above a $5 \mathrm{~cm} / \mathrm{s}^{2}$ acceleration threshold $\left(C A V_{5}\right.$; [21]) has been shown to be an efficient predictor of liquefaction triggering and consequences of liquefaction for shallow foundations [17-21]. These applications are of interest for practitioners in New Zealand. Equation 3 defines $C A V_{5}$, where $\chi\langle a(t)\rangle$ is a filter that is zero if $|a(t)|$ is less than $5 \mathrm{~cm} / \mathrm{s}^{2}$.

$$
C A V_{5}=\int_{0}^{t_{d}} \chi\langle a(t)\rangle|a(t)| d t
$$

Other permutations, such as standardized $C A V\left(C A V_{S T D}\right)$ and damage potential $C A V\left(C A V_{D P}\right)$ are primarily applicable in the analysis of nuclear power plants [22, 23], which are not found in New Zealand. These versions of $C A V$ are therefore excluded from consideration in this study.

Peak incremental ground velocity $\left(V_{g i}\right)$ is defined as the absolute area under the largest acceleration pulse in a record. $V_{g i}$ is a relatively novel, non-spectral, peak transient IM. $V_{g i}$ has been shown to be useful in predicting the maximum excursion of a base isolator [24], or the residual tilt of a shallow-founded structure on liquefiable ground [19]. $V_{g i}$ is defined by Equation 4 , where $t_{1, i}$ and $t_{2, i}$ are the times when the $i$-th acceleration pulse in a record begins and ends, respectively.

$$
V_{g i}=\max _{i}\left[\int_{t_{1, i}}^{t_{2, i}}|a(t)| d t\right]
$$

Significant duration [25] is particularly useful when paired with another IM (e.g., [26-28]). This study considers the 5\% to 75\% significant duration $\left(D_{5-75}\right)$ and the $5 \%$ to $95 \%$ significant duration $\left(D_{5-95}\right)$. These durations are defined as the time that passes between the accumulation of $5 \%$ and either $75 \%$ or $95 \%$ of the total Arias intensity of a ground motion record. This study considers $I_{A}, C A V, C A V_{5}$, and $V_{g i}$ in units of $\mathrm{cm} / \mathrm{s}$ and $D_{5-75}$ and $D_{5-95}$ in units of s.

\section{Database}

The raw database used in this study consists of 4,291 ground motion records from 276 earthquakes recorded at 398 sites in New Zealand, gathered from the NZSMD. The database includes recordings from crustal, slab, and interface events, and from stations in all GeoNet regions except for Auckland and Northland. Figures 1 and 2 show the locations of the earthquake epicentres and strong motion stations included in the database.

The NZSMD provides metadata for all parameters considered in this study with one exception: the path distance within the Taupo Volcanic Zone $\left(R_{T V Z}\right)$. Geologists have studied the TVZ extensively (e.g., [29-31]). McVerry et al. [32] and Bradley [33] included special considerations for increased anelastic attenuation of seismic waves traveling through the TVZ, demonstrating its relevance to the development of New Zealand-specific GMMs

In order to investigate the influence of $R_{T V Z}$ on the IMs and significant durations considered here, it must be calculated for all records in the NZSMD and appended to their metadata. This study defines the boundaries of the TVZ according to the boundaries of the "whole TVZ" in Cousins et al. [34]. That study found this definition of the TVZ to be more appropriate than definitions of the "central volcanic region" or the "young TVZ." Figure 3 shows the adopted definition of the TVZ. Further, this study defines $R_{T V Z}$ as the length of the portion of the surface projection of the source-to-site path. The calculated values of $R_{T V Z}$ were validated against the database used by McVerry et al. [32] and Bradley [33].

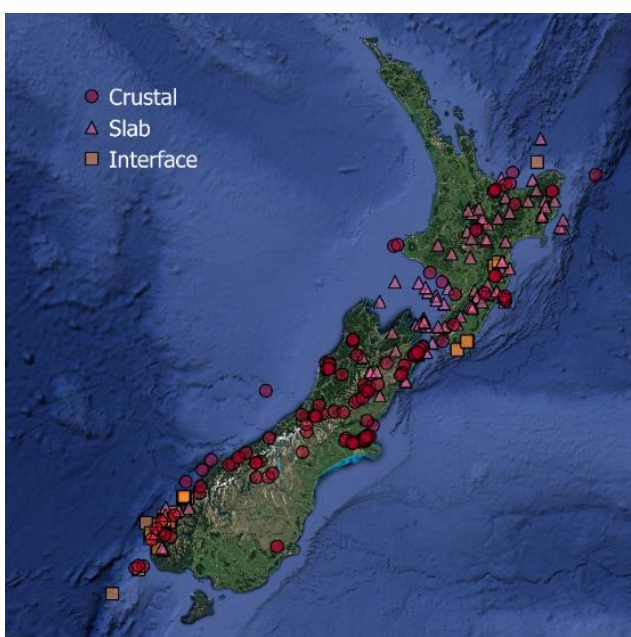

Figure 1: Earthquake epicentres included in the database according to tectonic class.

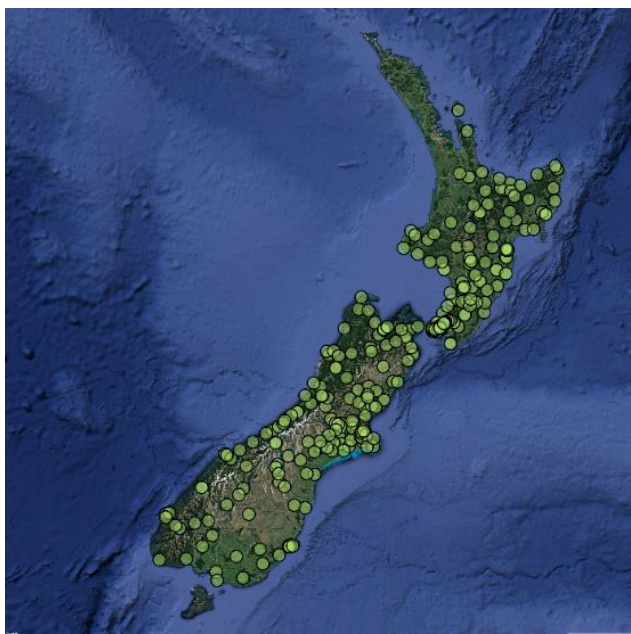

Figure 2: Strong motion recording stations included in the database.

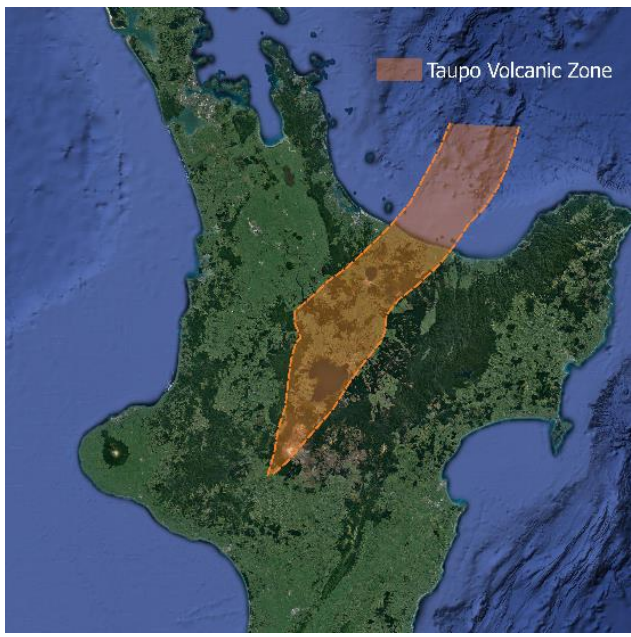

Figure 3: Definition of the boundaries of the Taupo Volcanic Zone.

The raw database of NZSMD records was filtered according to magnitude and distance to exclude insignificant records. First, only events with moment magnitude greater than 4.0 were included. Second, the magnitude-dependent distance filter given by Equation 5 was applied.

$$
R_{\text {rup }} \leq 77.5 M_{W}-220
$$


Additionally, the database is filtered to include only earthquakes that were recorded by at least four strong motion stations. The final, filtered database includes 3,293 records from 172 earthquakes at 384 sites. Figure 4 shows the magnitude-distance domain of the dataset, as well as the region removed by the filter.

Table 1 reports the regional distribution of the events and records included in the database. Although many events are included from several regions, the total number of records is dominated by the Canterbury and Wellington and Marlborough regions, reflecting the density of strong motion stations there. The Otago and Southland region is the least represented region in the database.

Table 2 shows the distribution of the database according to tectonic environment. The database consists mainly of records from crustal and slab earthquakes, with relatively fewer interface events. Most of the interface events included occurred in the Fiordland region, although two from the Nelson and West Coast and four from the Wellington and Marlborough region are also included.

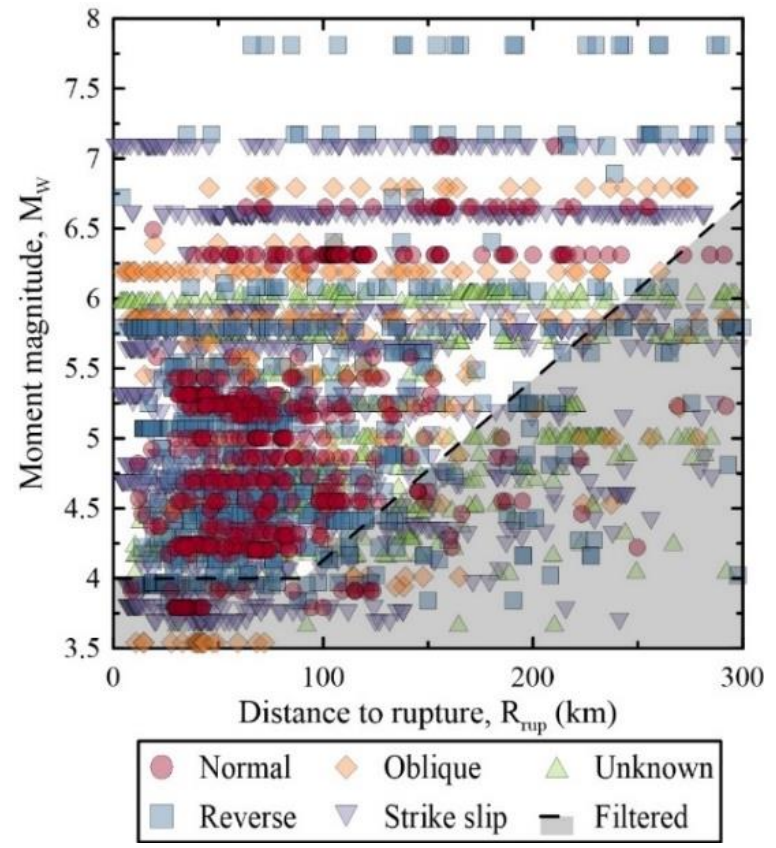

Figure 4: The magnitude-distance domain of the dataset.

\section{Regression Methodology}

\section{Median Predictions and Uncertainty}

The functional forms used in this study can be generalized according to Equation 6.

$$
\ln \left(y_{e s}\right)=F_{\text {source }}+F_{\text {path }}+F_{\text {site }}+\delta B_{e}+\delta W_{e s}
$$

where $y_{e s}$ is the observed value of a given IM or significant duration recorded during the $e$-th earthquake at the $s$-th site, and $F_{\text {source }}, F_{\text {path }}$, and $F_{\text {site }}$ are terms that describe the influence of source, path, and site parameters, respectively.

The models in this study are developed using mixed-effects regression [35] according to Stafford [36]. In this methodology, model coefficients (i.e., the median predictions) and uncertainty are formulated simultaneously. The uncertainty is quantified in terms of between- and within-event standard deviations ( $\tau$ and $\phi$, respectively). Correspondingly, the model errors are decomposed into between- and within-event components $\left(\delta B_{e}\right.$ and $\delta W_{e s}$, the errors for the $e$-th event and the $s$-th station in that event, respectively).
Table 1: Regional distribution of events and records in the database.

\begin{tabular}{lccc}
\hline \multicolumn{1}{c}{ Region } & Code & $\begin{array}{c}\text { No. } \\
\text { events }\end{array}$ & $\begin{array}{c}\text { No. } \\
\text { records }\end{array}$ \\
\hline Canterbury & CNB & 47 & 1,310 \\
\hline Fiordlands & FRD & 54 & 340 \\
\hline Gisborne & GSB & 15 & 128 \\
\hline Hawke's Bay & HWK & 14 & 150 \\
\hline Nelson and West Coast & NWC & 35 & 334 \\
\hline Otago and Southland & OTG & 2 & 13 \\
\hline Taranaki & TNK & 7 & 103 \\
\hline Tongariro and Bay of Plenty & TNG & 32 & 290 \\
\hline Wellington and Marlborough & WLM & 70 & 1,623 \\
\hline
\end{tabular}

Table 2: Regional distribution of events and records in the database.

\begin{tabular}{lcc}
\hline Tectonic environment & No. events & No. records \\
\hline Crustal & 80 & 1,737 \\
\hline Slab & 71 & 1,298 \\
\hline Interface & 21 & 258 \\
\hline
\end{tabular}

Unlike the other IMs considered here, $C A V_{5}$ can take on zero values based on its definition. Developing the model for $C A V_{5}$ uses an alternative version of mixed-effects regression that allows for censoring and conditioning on the IM exceeding zero. This study follows the methodology of Stafford [37], which applied censored mixed-effects regression to model conditional duration (i.e., duration that is considered nonzero if $P G A$ exceeds some threshold). $C A V_{5}$ is conditioned on $P G A \geq$ $5 \mathrm{~cm} / \mathrm{s}^{2}$.

The censored mixed-effects regression method requires knowledge or estimation of the random effects of the conditioning IM (in this case, $P G A$ ). This study estimates $\delta B_{e}(P G A)$ amd $\delta W_{e s}(P G A)$ by calculating the residuals for each record using the Bradley [33] GMM and decomposing them using linear mixed-effects regression. These random effects are jointly distributed with those of the $C A V_{5}$ model. For details regarding the calculation of model coefficients using maximum likelihood estimation, see Stafford [37]. In this case, the results are similar those obtained without conditioning because most records with $C A V_{5}=0$ are excluded from consideration by the magnitude-distance filter given by Equation 6 and shown in Figure 4.

Initially, this methodology yields homoscedastic (i.e., constant with all model parameters) estimates of the standard deviations. Heteroscedasticity is investigated subsequently to identify any trends in model uncertainty. This is accomplished by examining the standard deviations as calculated using subsets of model errors binned according to the various input parameters, as is often in the case in GMM development (e.g., [4]). 
Separate models are developed for crustal, slab, and interface events. Per Table 2, the database of records from interface events is substantially smaller than for the other two types. Implications of database size on the potential for bias and on model uncertainty are discussed.

\section{Spatial Autocorrelation}

Foulser-Piggott and Stafford [38] previously explored spatial autocorrelation of the errors in their model for $I_{A}$, and concluded that no generalizable trends were observed. This study revisits this question and seeks to identify trends that can be applied for New Zealand-specific incorporation of spatial autocorrelation into PSHA.

As in Foulser-Piggott and Stafford [38], this study analyses spatial autocorrelation using empirical semivariograms, which consist of calculated scatterplots of semivariance against separation distance. To be useful for forward analysis, functions must be fit to the empirical semivariogram data. Exponential, spherical, and Gaussian functional forms are typically used in this context [39]. This study uses the Gaussian form.

Cressie [40] provided a weighting scheme for the fitting of functions to empirical semivariograms. The weighting scheme places emphasis on small separation distances (i.e, the correlation among sites that are nearer to one another), and on points calculated with more underlying pairs of observations. For a given bin in the empirical semivariogram, the weight is simply the number of data point pairs in that bin divided by that bin's separation distance.

Empirical semivariograms are formulated for the within-event errors $\left(\delta W_{e S}\right)$ in each earthquake. Trends in the characteristics of the semivariograms are then explored as functions of various event parameters.

\section{MODEL DEVELOPMENT}

\section{Median Models}

\section{Functional Form Selection}

Each of these terms in Equation $6\left(F_{\text {source }}, F_{\text {path }}\right.$, and $\left.F_{\text {site }}\right)$ is broken down further into terms that capture specific effects. The mathematical forms of these terms are selected from sets of candidate forms using cross validation, as described below.

The source term

In past GMMs, the source term has included a linear, quadratic, or logarithmic function of magnitude, sometimes a function of the earthquake depth (represented by either the focal depth, $H$, or the depth to top-of-rupture, $Z_{T O R}$ ), and sometimes a function of faulting mechanism. Equation 7 shows the general form for the source term.

$$
F_{\text {source }}=f_{\text {mag }}+f_{\text {dep }}+f_{\text {mech }}
$$

Table 3 shows the candidate forms for the magnitude term. These forms are five of the most common formulations of the influence of magnitude in GMMs. More complex, multilinear forms (e.g., that of [2]) are not considered. The possibility of excluding the magnitude term is not considered.

Table 4 shows the candidate forms for the depth term. Functions of either $H$ or $Z_{T O R}$ are considered, and reflect the variety of depth terms seen in the literature (e.g., $[2,8,10,11,33])$. For this and all subsequent terms, the possibility of excluding the term completely is also considered.

The final component of the source term consists of flags for faulting mechanisms $\left(f_{R}\right.$ is a flag that is 1 for reverse faulting and 0 otherwise and $f_{N}$ is a flag that is 1 for normal faulting and
0 otherwise). Flags such as these are ubiquitous in the literature (e.g., $[5,10])$. Table 5 reports the combinations of flags considered in this study.

Table 3: Possible forms of the magnitude term.

\begin{tabular}{cc}
\hline ID & Magnitude term, $\boldsymbol{f}_{\text {mag }}$ \\
\hline 1 & $a_{0}+a_{1} M_{W}$ \\
\hline 2 & $a_{0}+a_{1} M_{W}+a_{2} M_{W}^{2}$ \\
\hline 3 & $a_{0}+a_{1} \ln \left(M_{W}\right)$ \\
\hline 4 & $a_{0}+a_{1} M_{W}+a_{2} \ln \left(M_{W}\right)$ \\
\hline 5 & $a_{0}+a_{1}\left(M_{W}-6\right)+a_{2} \ln \left(M_{W} / 6\right)$ \\
\hline
\end{tabular}

Table 4: Possible forms of the depth term.

\begin{tabular}{|c|c|c|}
\hline ID & \multicolumn{2}{|c|}{ Depth term, $f_{d e p}$} \\
\hline 1 & \multicolumn{2}{|c|}{$a_{3} Z_{T O R}$} \\
\hline 2 & \multicolumn{2}{|c|}{$a_{3}\left(\min \left[Z_{T O R}, a_{4}\right]-4\right)$} \\
\hline 3 & $\left\{\begin{array}{r}a_{3} \frac{Z_{T O R}}{20}, \\
a_{3},\end{array}\right.$ & $\begin{array}{l}Z_{T O R}<20 \\
20 \leq Z_{T O R}\end{array}$ \\
\hline 4 & \multicolumn{2}{|c|}{$a_{3} H$} \\
\hline 5 & \multicolumn{2}{|c|}{$a_{3} \max (0, H-30)$} \\
\hline
\end{tabular}

Table 5: Possible forms of the mechanism term.

\begin{tabular}{cc}
\hline ID & Mechanism term, $\boldsymbol{f}_{\text {mech }}$ \\
\hline 1 & $a_{5} f_{R}$ \\
\hline 2 & $a_{5} f_{N}$ \\
\hline 3 & $a_{5} f_{R}+a_{6} f_{N}$ \\
\hline
\end{tabular}

The path term

The path term is primarily a function of the distance between the source and the site. Typically, this distance is parameterized as the distance-to-rupture $\left(R_{\text {rup }}\right)$ or the Joyner-Boore distance $\left(R_{J B}\right)$, although the hypocentral distance $\left(R_{\text {hypo }}\right)$ is also used in certain applications. The perpendicular distance from the fault strike to the site $\left(R_{X}\right)$ is sometimes included to examine hanging wall effects. Lastly, the distance travelled through the Taupo Volcanic Zone $\left(R_{T V Z}\right)$ has particular relevance to New Zealandspecific ground motion models. The path term in this study follows the form shown by Equation 8 .

$$
F_{\text {path }}=f_{\text {dist }, \text { log }}+f_{\text {dist,lin }}+f_{\text {tvz }}+f_{\text {hng }}
$$

Many GMMs use a logarithmic distance term. Table 6 reports the candidate forms of this term. The term may or may not be magnitude-dependent and may or may not include a fictitious depth term. The fictitious depth $(h)$ allows the functional form to capture near-source saturation (e.g., [3]). In these equations, $R$ may be either $R_{\text {rup }}$ or $R_{J B}$. For equations containing $\ln (R)$, 
$\ln \left(R_{J B}+0.01\right)$ is used in order to avoid taking the log in cases where $R_{J B}=0$. Some GMMs have also included a linear distance term (e.g., [9-10]). Table 7 reports the possible forms for this term.

Table 8 provides two candidate forms for a near-source adjustment. In both cases, the adjustment affects only records with $R$ shorter than some threshold value $\left(R_{n s}\right)$. Such an adjustment may be needed because relatively few records are available at very short distances, while these distances are of particular engineering interest.

Table 6: Possible forms of the logarithmic distance term.

\begin{tabular}{cc}
\hline ID & Logarithmic distance term, $\boldsymbol{f}_{\text {dist }, \text { log }}$ \\
\hline 1 & $b_{1} \ln (R)$ \\
\hline 2 & {$\left[b_{1}+b_{2} M_{W}\right] \ln (R)$} \\
\hline 3 & $b_{1} \ln \left(\sqrt{R^{2}+h^{2}}\right)$ \\
\hline 4 & {$\left[b_{1}+b_{2} M_{W}\right] \ln \left(\sqrt{R^{2}+h^{2}}\right)$} \\
\hline
\end{tabular}

Table 7: Possible forms of the linear distance term.

\begin{tabular}{|c|c|c|}
\hline ID & \multicolumn{2}{|c|}{ Linear distance term, $\boldsymbol{f}_{\text {dist,lin }}$} \\
\hline 1 & $b_{3} R$ & \\
\hline 2 & $\left\{\begin{array}{r}b_{3} R \\
b_{3} R_{1}+b_{4}\left(R-R_{1}\right)\end{array}\right.$ & $\begin{array}{l}R<R_{1} \\
R_{1} \leq R\end{array}$ \\
\hline
\end{tabular}

Table 8: Possible forms of the near-source term.

\begin{tabular}{cc}
\hline ID & Linear distance term, $\boldsymbol{f}_{\text {dist }, \text { lin }}$ \\
\hline 1 & $b_{5} \max \left(R_{n s}-R, 0\right)$ \\
\hline 2 & $b_{5} \max \left(\ln \left(R_{n s} / R\right), 0\right)$ \\
\hline
\end{tabular}

The effects of the TVZ on the attenuation of seismic waves have been studied [41-42] and incorporated into GMMs [32-33]. Table 9 reports the four candidate forms of the TVZ term. Simplified alternatives are included in addition to the magnitude dependent version used by Bradley [33].

Table 10 shows the candidate forms of the hanging wall term. In these equations, $f_{H W}$ is a flag that is equal to 1 if $R_{X}$ is positive and 0 otherwise, and $\delta$ is the dip angle of the earthquake rupture plane. Similar forms are found in the literature (e.g., [6, 33]). More complex hanging wall terms are not considered (e.g., $[2,5])$.

The site term

The site term (generalized by Equation 9) consists of terms for the site stiffness $\left(f_{\text {soil }}\right)$ and sediment depth effects $\left(f_{\text {sed }}\right)$. Site terms in GMMs reflect the influence of surface geology on recorded ground motions, which is usually represented using two proxies: the time-averaged shear wave velocity of the top $30 \mathrm{~m}$ of soil $\left(V_{S, 30}\right)$ and the depth to a layer with shear wave velocity of $1,000 \mathrm{~m} / \mathrm{s}$ or greater $\left(Z_{1.0}\right)$.

$$
F_{\text {site }}=f_{\text {soil }}+f_{\text {sed }}
$$

Table 11 reports the candidate forms considered for the site stiffness term. The logarithmic form (i.e., the first candidate) is ubiquitous in the literature of GMMs for non-spectral IMs and significant durations, and the possible inclusion of a capping velocity is also considered.

The candidate forms of the sediment depth term are reported in Table 12. Such terms may or may not include dependence on an expected value of $Z_{1.0}\left(\mu_{Z_{1.0}}\right)$ that comes from a model that correlates $Z_{1.0}$ and $V_{S, 30}$.

Table 9: Possible forms of the TVZ term.

\begin{tabular}{lc}
\hline ID & TVZ term, $\boldsymbol{f}_{\boldsymbol{t} v \mathbf{z}}$ \\
\hline 1 & $b_{6} R_{T V Z}$ \\
\hline 2 & $b_{6} \frac{R_{T V Z}}{R}$ \\
\hline 3 & $b_{6}\left(1+b_{7} \frac{R_{T V Z}}{R}\right) R$ \\
\hline 4 & {$\left[b_{6}+\frac{b_{7}}{\cosh \left[\max \left(M_{W}-b_{8}, 0\right)\right]}\right]\left(1+\frac{R_{T V Z}}{R}\right) R$} \\
\hline
\end{tabular}

Table 10: Possible forms of the hanging wall term.

ID Hanging wall term, $f_{h n g}$

$1 \quad b_{8} f_{H W} \tanh \left(\frac{R_{X} \cos ^{2} \delta}{b_{9}}\right)\left[1-\frac{\sqrt{R_{J B}^{2}+Z_{T O R}^{2}}}{R_{\text {rup }}+0.001}\right]$

$2 \quad b_{8} f_{H W} \tanh \left(\frac{R_{X}|\cos \delta|}{b_{9}}\right)\left[1-\frac{\sqrt{R_{J B}^{2}+Z_{T O R}^{2}}}{R_{\text {rup }}+0.001}\right]$ 
Table 11: Possible forms of the site stiffness term.

\begin{tabular}{cc}
\hline ID & Site stiffness term, $\boldsymbol{f}_{\text {soil }}$ \\
\hline 1 & $c_{1} \ln \left(V_{S, 30}\right)$ \\
\hline 2 & $c_{1} \ln \left(\min \left(V_{S, 30}, V_{1}\right)\right)$ \\
\hline
\end{tabular}

Table 12: Possible forms of the sediment depth term.

\begin{tabular}{cc}
\hline ID & Sediment depth term, $\boldsymbol{f}_{\text {sed }}$ \\
\hline 1 & $c_{2}\left(1-\frac{1}{\cosh \left[c_{3} \max \left(0, Z_{1.0}-c_{4}\right)\right.}\right)$ \\
\hline 2 & $c_{2}\left(Z_{1.0}-\mu_{Z_{1.0}}\right)$ \\
\hline
\end{tabular}

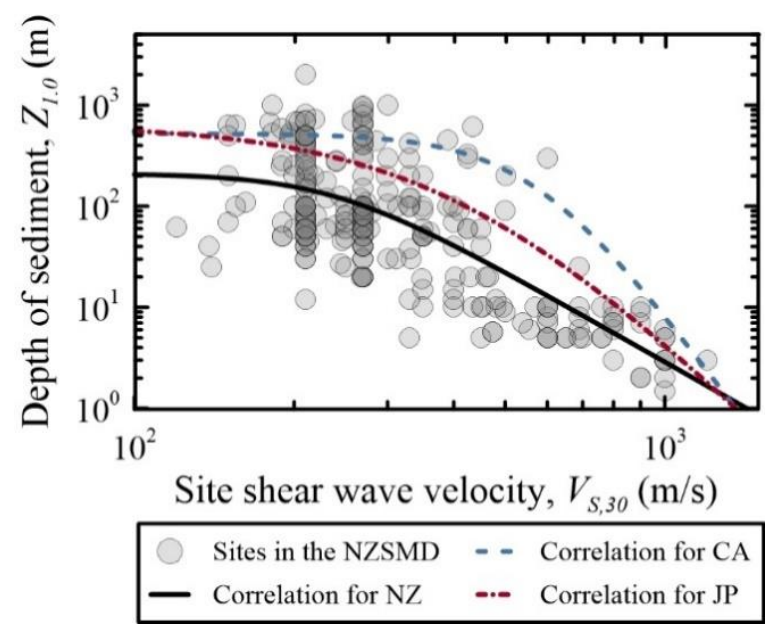

Figure 5: New Zealand-specific $Z_{1.0}$ correlation model.

Boore et al. [4] and Chiou and Youngs [6] both note that the relationship between $Z_{1.0}$ and $V_{S, 30}$ has regional differences, but neither provide a relationship for sites in New Zealand. Equation 10 provides such a correlation based exclusively on the NZSMD, using data from all recording stations:

$$
\ln \left(\mu_{Z_{1.0}}\right)_{N Z}=\frac{-2.98}{4} \ln \left(\frac{V_{S, 30}^{4}+237^{4}}{1428^{4}+237^{4}}\right)
$$

This equation follows the same form as the existing correlations for sites in California (CA) and Japan (JP) provided in [4] Figure 5 shows the performance of all three correlation models on the sites in the NZSMD. Generally, the value of $\mu_{Z_{1.0}}$ using the New Zealand-specific model is smaller than those provided by the Californian or Japanese correlations.
The selected forms

Functional forms are determined for each IM and significant duration in a greedy forward stepwise manner. First, regressions are performed for each candidate form of the magnitude term (Table 3). These forms are evaluated using $k$ fold cross validation with 10 folds (see, e.g., [43]), and the form with the smallest validation error is selected. When separating the folds, records from each earthquake are not separated (i.e., all records from a given earthquake are included in the same fold). Then, a depth term is added, and each candidate form of the depth term is tested (Table 4). The depth term which yields the smallest validation error is added, or, if none improves the validation error from the previous step, the depth term is omitted. This proceeds for one term at a time in a similar fashion for Tables 5 through 12.

There is agreement on two forms for each tectonic class: one for the IMs, and one for the significant durations. Equation 11 provides a general form for the GMMs developed in this study. This equation is applicable for all IMs and all tectonic classes, but some coefficients will be zero in some cases.

$$
\begin{aligned}
& \ln \left(\hat{y}_{e S}\right)=a_{0}+a_{1} M_{W}+a_{2} \ln \left(M_{W}\right)+a_{3} Z_{T O R}+a_{4} f_{N}+ \\
& a_{5} f_{R}+\left[b_{1}+b_{2} M_{W}\right] \ln \left(\sqrt{R_{J B}^{2}+h^{2}}\right)+b_{3} R_{J B}+ \\
& b_{4} \frac{R_{T V Z}}{R_{\text {rup }}}+c_{1} \ln \left(V_{S, 30}\right)+c_{2}\left(Z_{1.0}-\mu_{Z_{1.0}}\right)
\end{aligned}
$$

The functional form includes linear and logarithmic terms for $M_{W}$ dependence and linear and logarithmic term for $R_{J B}$ dependence which includes near-source saturation in the form of $h$. The logarithmic term for $R_{J B}$ is magnitude-dependent. The influence of $R_{T V Z}$ is related to its ratio with $R_{\text {rup }}$. The form also includes dependence on depth and the flag for normal events. Site effects are a function of both $V_{S, 30}$ and $Z_{1.0}$. The form does not include a term for hanging wall effects, suggesting that these effects may be more nuanced for peak transient spectral IMs.

Tables 12 through 14 provide the coefficients for median predictions of the models for the RotD50 and RotD100 components of all IMs and the models for significant duration for shallow crustal, inslab, and interface events, respectively. All coefficients in these tables are significant at the 5\% level, and many are significant below the $0.1 \%$ level. This result is expected because the cross-validation approach to form selection will tend to exclude terms with insignificant coefficients. Significance levels and standard errors are not reported for concision.

The models for shallow crustal events exclude the influence of the Taupo volcanic zone because very few records with nonzero $R_{T V Z}$ exist from crustal earthquakes (20 records of 1,737). Increasing the ratio of $R_{T V Z}$ to $R_{\text {rup }}$ generally decreases the predicted value of $I_{A}$, increases most other IMs, and does not affect significant duration. 
Table 13: Model coefficients for the median models and uncertainty around them for shallow crustal events.

\begin{tabular}{|c|c|c|c|c|c|c|c|c|c|c|c|c|c|c|c|c|c|c|c|c|c|}
\hline$\theta$ & 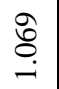 & 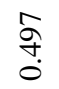 & 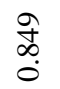 & $\begin{array}{l}\text { fô } \\
\stackrel{0}{0}\end{array}$ & 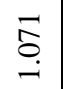 & $\begin{array}{l}\infty \\
\stackrel{+}{0}\end{array}$ & $\begin{array}{l}\tilde{\delta} \\
\stackrel{0}{0}\end{array}$ & $\begin{array}{l}\infty \\
\stackrel{0}{0} \\
0\end{array}$ & $\stackrel{\infty}{\stackrel{\infty}{+}}$ & $\underset{+}{ \pm}$ & $\theta$ & $\stackrel{\mathscr{\otimes}}{\stackrel{\leftrightarrow}{-}}$ & \begin{tabular}{c} 
y \\
\multirow{n}{0}{} \\
0
\end{tabular} & $\begin{array}{l}\stackrel{\infty}{\infty} \\
\stackrel{0}{0}\end{array}$ & 仓̊. & $\underset{\mathscr{\infty}}{\stackrel{0}{0}}$ & 先 & 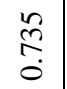 & तై & $\begin{array}{l}\bar{\infty} \\
\vdots \\
0\end{array}$ & $\begin{array}{l}+ \\
\stackrel{+}{+} \\
0\end{array}$ \\
\hline N & $\frac{9}{\stackrel{9}{0}}$ & $\frac{2}{m}$ & 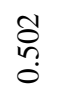 & $\begin{array}{l}\bar{\approx} \\
\stackrel{0}{0}\end{array}$ & 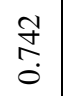 & 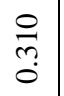 & 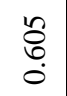 & 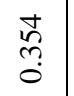 & 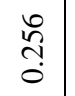 & 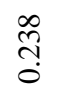 & r & $\begin{array}{l}8 \\
0\end{array}$ & 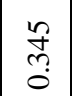 & $\begin{array}{l}8 \\
n \\
0\end{array}$ & 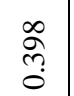 & 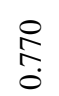 & 哭 & $\stackrel{0}{n}$ & $\underset{0}{0}$ & 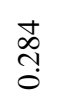 & $\begin{array}{l}\overline{\mathbb{N}} \\
\text { S }\end{array}$ \\
\hline $\mathcal{N}$ & 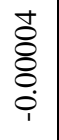 & 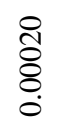 & $\begin{array}{l}\stackrel{n}{0} \\
\stackrel{8}{8} \\
\vdots \\
0\end{array}$ & $\begin{array}{l}\overline{0} \\
\overline{8} \\
0 \\
0\end{array}$ & $\begin{array}{l}\text { ¿े } \\
8 \\
8 \\
0 \\
i\end{array}$ & $\begin{array}{l}\infty \\
\stackrel{\infty}{0} \\
\stackrel{0}{0} \\
\dot{0}\end{array}$ & $\begin{array}{l}\stackrel{t}{0} \\
\stackrel{8}{0} \\
\vdots \\
0\end{array}$ & $\begin{array}{l}0 \\
\stackrel{0}{0} \\
\vdots \\
0 \\
0\end{array}$ & ' & ' & $\widetilde{v}$ & 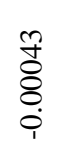 & $\begin{array}{l}0 \\
\delta \\
0 \\
0 \\
\dot{1}\end{array}$ & $\begin{array}{l}\infty \\
8 \\
8 \\
0 \\
0 \\
\end{array}$ & 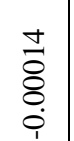 & 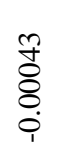 & $\begin{array}{l}0 \\
\delta \\
0 \\
0 \\
0\end{array}$ & $\begin{array}{l}\hat{8} \\
8 \\
0 \\
0\end{array}$ & $\begin{array}{l}\frac{\Delta}{8} \\
\stackrel{8}{0} \\
0 \\
0\end{array}$ & ' & \\
\hline v & $\begin{array}{l}n \\
\mathfrak{b} \\
\stackrel{0}{i} \\
1\end{array}$ & $\begin{array}{l}\stackrel{\infty}{J} \\
\stackrel{5}{+} \\
\stackrel{1}{1}\end{array}$ & \begin{tabular}{l}
$n$ \\
\multirow{0}{0}{} \\
0 \\
$i$
\end{tabular} & 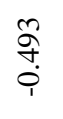 & $\begin{array}{l}\underset{d}{0} \\
\stackrel{0}{i}\end{array}$ & \begin{tabular}{l} 
స̃ \\
\multirow{I}{*}{} \\
$\stackrel{1}{1}$
\end{tabular} & $\begin{array}{l}n \\
n \\
n \\
i \\
1\end{array}$ & 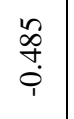 & $\begin{array}{l}1 \\
\delta \\
0 \\
\dot{i}\end{array}$ & 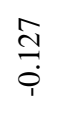 & v & 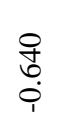 & 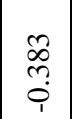 & 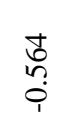 & 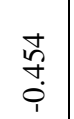 & 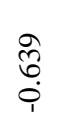 & 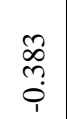 & $\begin{array}{l}\bar{n} \\
\tilde{n} \\
i\end{array}$ & $\begin{array}{l}\text { fo } \\
\text { i }\end{array}$ & 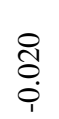 & $\frac{\grave{T}}{\stackrel{0}{i}}$ \\
\hline $0^{+}$ & ' & ' & ' & ' & ' & ' & ' & ' & ' & , & $\Omega^{+}$ & $\begin{array}{l}\stackrel{8}{+} \\
\underset{+}{+} \\
\stackrel{\text { in }}{i}\end{array}$ & 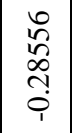 & $\begin{array}{l}\hat{\infty} \\
\stackrel{\infty}{0} \\
\rightarrow \\
\rightarrow\end{array}$ & $\begin{array}{l}\infty \\
\vec{\sigma} \\
\vdots \\
0 \\
1\end{array}$ & 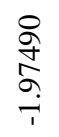 & 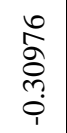 & $\begin{array}{l}\frac{n}{n} \\
\frac{n}{2} \\
\frac{1}{1}\end{array}$ & 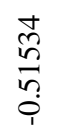 & ' & \\
\hline$\rho^{m}$ & ' & ' & ' & & , & ' & ' & , & $\stackrel{0}{\circ}$ & $\stackrel{0}{0}$ & $\stackrel{m}{s}$ & & & ' & ' & ' & & & ' & ' & \\
\hline$s$ & 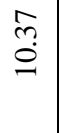 & $\stackrel{\infty}{\stackrel{0}{0}}$ & $\stackrel{\vartheta}{\stackrel{\vec{\lambda}}{\vec{v}}}$ & $\begin{array}{l}\bar{\infty} \\
\sigma\end{array}$ & $\stackrel{f}{\circ}$ & ڤ్ & 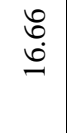 & $\begin{array}{l}\infty \\
\infty \\
\sigma\end{array}$ & $\begin{array}{l}\infty \\
\stackrel{\infty}{i} \\
i\end{array}$ & $\stackrel{\infty}{\stackrel{\infty}{\sim}}$ & $\simeq$ & $\begin{array}{l}+ \\
\text { के } \\
m\end{array}$ & $\begin{array}{l}\tilde{\sigma} \\
\ddot{m}\end{array}$ & $\begin{array}{l}\stackrel{\sim}{*} \\
\text { }\end{array}$ & 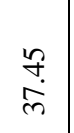 & $\begin{array}{l}\infty \\
\infty \\
\ddot{n}\end{array}$ & $\begin{array}{l}\infty \\
\infty \\
\infty \\
\infty\end{array}$ & 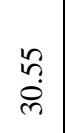 & $\frac{n}{\hat{b}}$ & $\frac{\sigma}{\hat{n}}$ & $\frac{a}{\infty}$ \\
\hline$\sigma^{2}$ & $\begin{array}{l}\stackrel{0}{n} \\
\stackrel{0}{0}\end{array}$ & $\stackrel{\hat{\sigma}}{\circ}$ & $\stackrel{\infty}{\stackrel{\infty}{?}}$ & 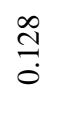 & $\frac{n}{n}$ & $\begin{array}{l}0 \\
\stackrel{0}{0} \\
0\end{array}$ & $\stackrel{\Xi}{\exists}$ & $\stackrel{m}{=}$ & $\begin{array}{l}\bar{m} \\
\vec{i}\end{array}$ & $\begin{array}{l}\vec{o} \\
\stackrel{0}{0}\end{array}$ & $\stackrel{s}{2}$ & 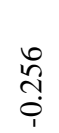 & $\begin{array}{l}\infty \\
0 \\
0 \\
0 \\
1\end{array}$ & $\underset{+}{\stackrel{+}{0}}$ & 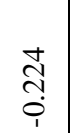 & $\begin{array}{l}\hat{\overbrace{}} \\
\text { î̀ }\end{array}$ & $\begin{array}{l}0 \\
\text { o. } \\
\text { in }\end{array}$ & 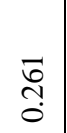 & $\frac{o}{\hat{N}}$ & $\stackrel{+}{\stackrel{ \pm}{0}}$ & 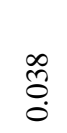 \\
\hline 5 & $\stackrel{\vec{m}}{\vec{m}}$ & $\underset{+}{+}$ & $\begin{array}{l}\text { ָे } \\
\stackrel{+}{+}\end{array}$ & 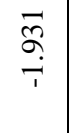 & 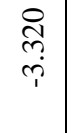 & 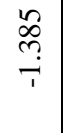 & $\begin{array}{l}\tilde{I} \\
\infty \\
\dot{\Gamma} \\
\dot{1}\end{array}$ & $\begin{array}{l}\infty \\
\stackrel{\infty}{\infty} \\
\stackrel{+}{\longrightarrow}\end{array}$ & $\stackrel{8}{\circ}$ & $\begin{array}{l}\stackrel{0}{\infty} \\
\stackrel{\infty}{0}\end{array}$ & 5 & 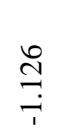 & $\begin{array}{l}\stackrel{\infty}{+} \\
\stackrel{+}{\dot{p}}\end{array}$ & $\begin{array}{l}\text { ô } \\
\stackrel{+}{+}\end{array}$ & 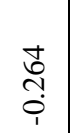 & $\stackrel{\circ}{\stackrel{\circ}{\rightarrow}}$ & 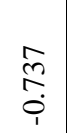 & $\begin{array}{l}\stackrel{R}{6} \\
\text { î } \\
i\end{array}$ & ڤ్. & $\stackrel{\infty}{\stackrel{\infty}{0}}$ & $\begin{array}{l}\text { d } \\
\text { Oे } \\
0\end{array}$ \\
\hline$\sigma^{\llcorner}$ & $\stackrel{n}{\stackrel{n}{9}}$ & 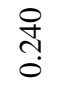 & $\stackrel{\vec{n}}{3}$ & $\stackrel{n}{0}$ & $\stackrel{m}{\stackrel{f}{0}}$ & $\stackrel{m}{\tilde{\sigma}}$ & $\begin{array}{l}\hat{\sigma} \\
\tilde{\sigma}\end{array}$ & $\begin{array}{l}\stackrel{n}{ \pm} \\
0 \\
0\end{array}$ & $\begin{array}{l}\mathfrak{r} \\
0 \\
0 \\
0\end{array}$ & $\stackrel{m}{=}$ & ص & & & ' & , & , & & & , & , & \\
\hline$\theta^{+}$ & $\begin{array}{l}\hat{s} \\
\text { ô } \\
\end{array}$ & $\begin{array}{l}\stackrel{v}{\ddagger} \\
\stackrel{i}{i}\end{array}$ & 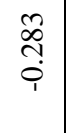 & 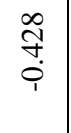 & $\begin{array}{l}\bar{\delta} \\
\stackrel{0}{\circ}\end{array}$ & $\begin{array}{l}\text { Pa } \\
\stackrel{9}{i}\end{array}$ & $\begin{array}{l}n \\
\stackrel{\infty}{+} \\
\stackrel{+}{\varphi}\end{array}$ & ণิ & $\underset{\tilde{U}}{\tilde{O}}$ & $\begin{array}{l}\text { ָे } \\
\text { ָ̦ }\end{array}$ & 8 & $\stackrel{n}{\frac{n}{0}}$ & $\begin{array}{l}1 \\
\delta \\
0 \\
0\end{array}$ & $\frac{\stackrel{0}{0}}{0}$ & $\begin{array}{l}+ \\
0 \\
0\end{array}$ & 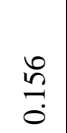 & ठ̊. & $\stackrel{m}{=}$ & $\underset{\square}{\overrightarrow{0}}$ & 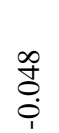 & $\hat{\sigma}$ \\
\hline శొ & $\stackrel{8}{o}$ & రి & $\begin{array}{l}\ddot{8} \\
\stackrel{9}{9}\end{array}$ & $\stackrel{m}{a}$ & $\stackrel{\text { ô }}{0}$ & $\begin{array}{l}\text { ๕̊ } \\
\vdots \\
1\end{array}$ & $\begin{array}{l}\infty \\
\stackrel{0}{0}\end{array}$ & $\stackrel{0}{\circ}$ & $\begin{array}{l}0 \\
\text { ठे } \\
\dot{\varphi}\end{array}$ & $\begin{array}{l}0 \\
\tilde{\rho} \\
\dot{\varphi}\end{array}$ & 8 & $\stackrel{0}{\circ}$ & $\stackrel{+}{8}$ & §̊̊ & $\stackrel{8}{0}$ & $\stackrel{0}{\circ}$ & 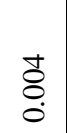 & $\begin{array}{l}+ \\
8 \\
0\end{array}$ & 令 & ס̊. & $\begin{array}{l}\overline{8} \\
0 \\
i\end{array}$ \\
\hline$\sigma^{N}$ & $\begin{array}{l}\stackrel{a}{0} \\
\stackrel{0}{0} \\
0\end{array}$ & 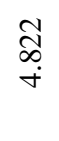 & $\begin{array}{l}\widehat{\hat{O}} \\
\stackrel{0}{0} \\
\stackrel{0}{0}\end{array}$ & $\begin{array}{l}\bar{\sigma} \\
\infty\end{array}$ & $\begin{array}{l}\infty \\
\infty \\
\infty \\
\infty\end{array}$ & 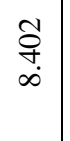 & $\begin{array}{l}f \\
\dot{0} \\
\dot{v} \\
\end{array}$ & 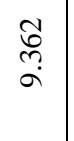 & $\begin{array}{l}\hat{\alpha} \\
\hat{i}\end{array}$ & 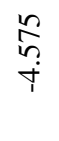 & $\mathcal{E}$ & 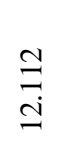 & ๙े & 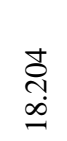 & 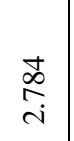 & $\begin{array}{l}\stackrel{9}{\infty} \\
\stackrel{\infty}{0} \\
\stackrel{0}{0}\end{array}$ & $\begin{array}{l}\bar{\infty} \\
\infty \\
\dot{\infty}\end{array}$ & $\begin{array}{l}\text { S. } \\
\stackrel{i}{+}\end{array}$ & 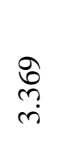 & $\begin{array}{l}a \\
\substack{0 \\
0}\end{array}$ & $\begin{array}{l}\text { : } \\
\stackrel{2}{0} \\
0\end{array}$ \\
\hline 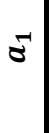 & कै & ?. & 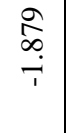 & $\begin{array}{l}\infty \\
\stackrel{\leftrightarrow}{+} \\
\stackrel{+}{+}\end{array}$ & $\begin{array}{l}n \\
\infty \\
n \\
n\end{array}$ & $\begin{array}{l}\hat{0} \\
\stackrel{n}{0} \\
1\end{array}$ & 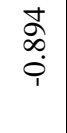 & $\begin{array}{l}n \\
\hat{n} \\
i\end{array}$ & $\stackrel{\leftrightarrow}{S}$ & $\stackrel{\infty}{\stackrel{\infty}{m}}$ & 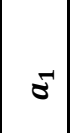 & 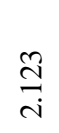 & $\stackrel{\circ}{\stackrel{\Upsilon}{I}}$ & 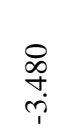 & $\begin{array}{l}\text { ते } \\
\text { त̂ }\end{array}$ & $\underset{\tilde{n}}{\vec{j}}$ & 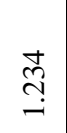 & $\begin{array}{l}\text { ડે } \\
\text { ָิ }\end{array}$ & $\underset{i}{\stackrel{0}{i}}$ & $\begin{array}{l}m \\
\substack{\infty \\
0 \\
i}\end{array}$ & 年 \\
\hline 8 & 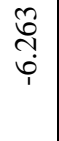 & 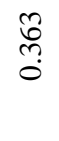 & 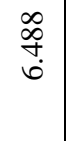 & $\underset{\mathscr{q}}{\stackrel{m}{r}}$ & 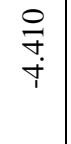 & مُ & 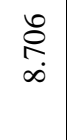 & $\begin{array}{l}\tilde{\sigma} \\
\dot{\sigma} \\
\dot{r}\end{array}$ & 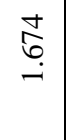 & $\underset{\text { dे }}{\text { iे }}$ & 8 & $\begin{array}{l}\infty \\
\sigma \\
\infty \\
\frac{\infty}{1}\end{array}$ & $\begin{array}{l}\text { ळे } \\
\text { i } \\
\text { i. }\end{array}$ & $\stackrel{\infty}{\stackrel{\infty}{0}}$ & 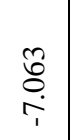 & 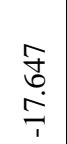 & $\underset{\substack{n \\
i}}{\stackrel{\infty}{n}}$ & 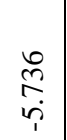 & 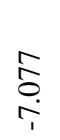 & $\stackrel{\Re}{\stackrel{0}{0}}$ & 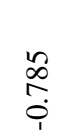 \\
\hline$\exists$ & $\stackrel{*}{*}$ & 莣 & $\stackrel{\mathrm{J}}{u}^{*}$ & $\ddot{*} \vec{s}$ & 恶 & 労 & $\begin{array}{l}\stackrel{*}{*} \\
\stackrel{\text { th }}{\vec{U}} \\
\vec{u}\end{array}$ & $\begin{array}{l}* \\
\vec{*} \\
\vec{\Delta}\end{array}$ & $\begin{array}{c}n \\
i \\
1 \\
a^{n}\end{array}$ & $\begin{array}{c}n \\
1 \\
1 \\
\vdots \\
a\end{array}$ & $\Sigma$ & $*^{*}$ & $\stackrel{*}{\vec{J}}$ & 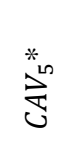 & $\vec{B}^{*} \tilde{s}$ & $\stackrel{*}{*}$ & 莡 & $\stackrel{\text { * }}{\stackrel{*}{*}}$ & $\stackrel{*}{*}$ & $\begin{array}{c}n \\
1 \\
1 \\
0^{n}\end{array}$ & $\begin{array}{c}2 \\
1 \\
1 \\
0 \\
0\end{array}$ \\
\hline
\end{tabular}

Table 14: Model coefficients for the median models and uncertainty around them for inslab events.

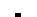


Table 15: Model coefficients for the median models and uncertainty around them for interface events.

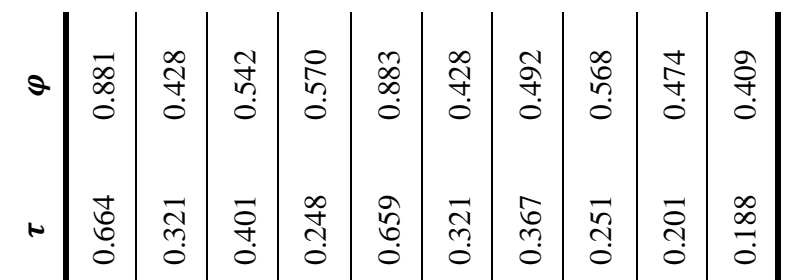

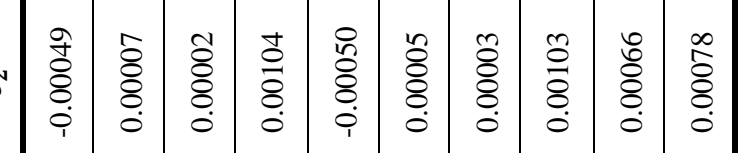

$$
\begin{aligned}
& \text { J }
\end{aligned}
$$

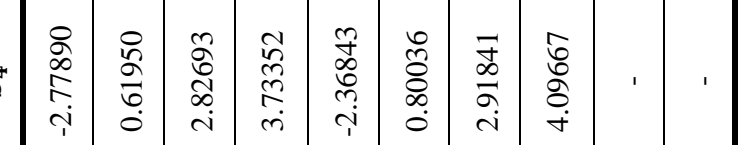

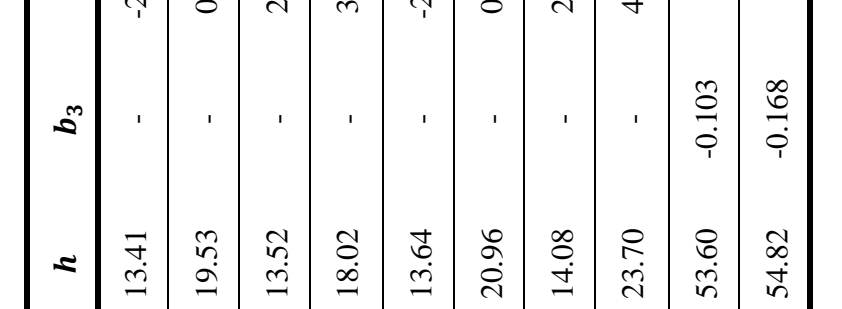

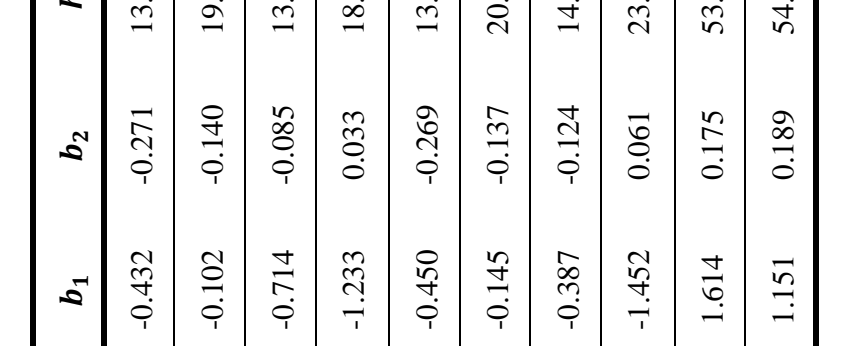

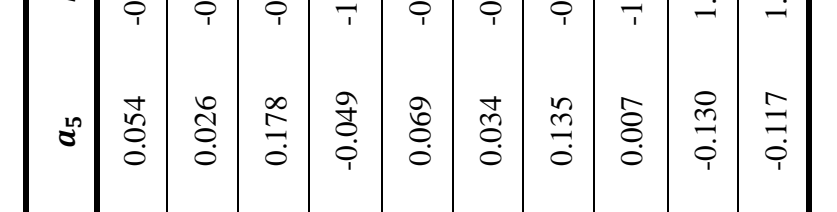

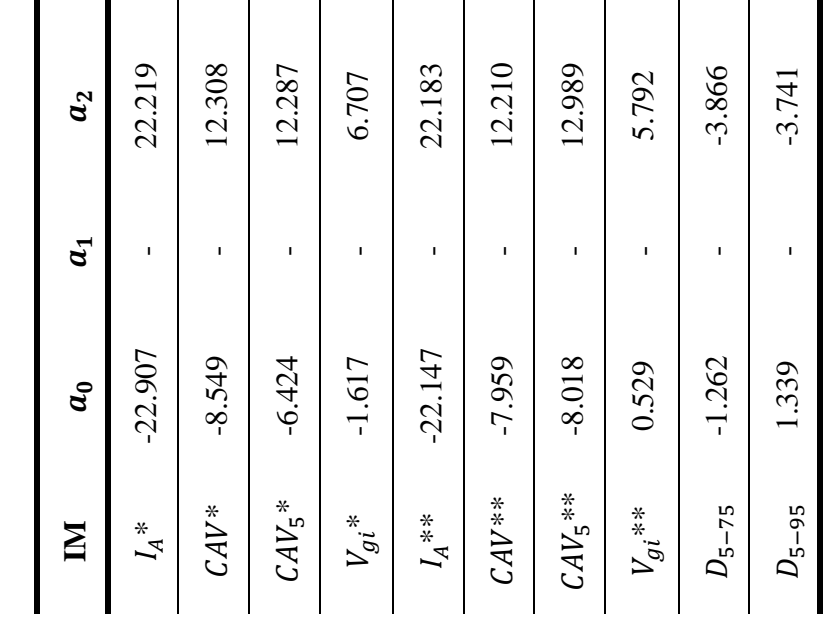

$$
\begin{aligned}
& \text { *RotD50; **RotD100 }
\end{aligned}
$$

\section{Model Performance}

This section presents the model errors against the predictor variables in order to demonstrate that the models are unbiased. Only $C A V$ and $D_{5-75}$ are presented for brevity, but the same trends are evident for all other IMs and for $D_{5-95}$. Figures 6 and 7 show the between-event residuals $\left(\delta B_{e}\right)$ as a function of the source parameters in the functional form, as well as for each region, for $C A V$ and $D_{5-75}$, respectively. The between-event residuals pass Lilliefors [44] tests for normality for all IMs and significant durations. There is no evident bias on the source parameters and no distinct regional bias, except for the cases of the Otago and Southland and Taranaki regions, both of which are underrepresented in the database.
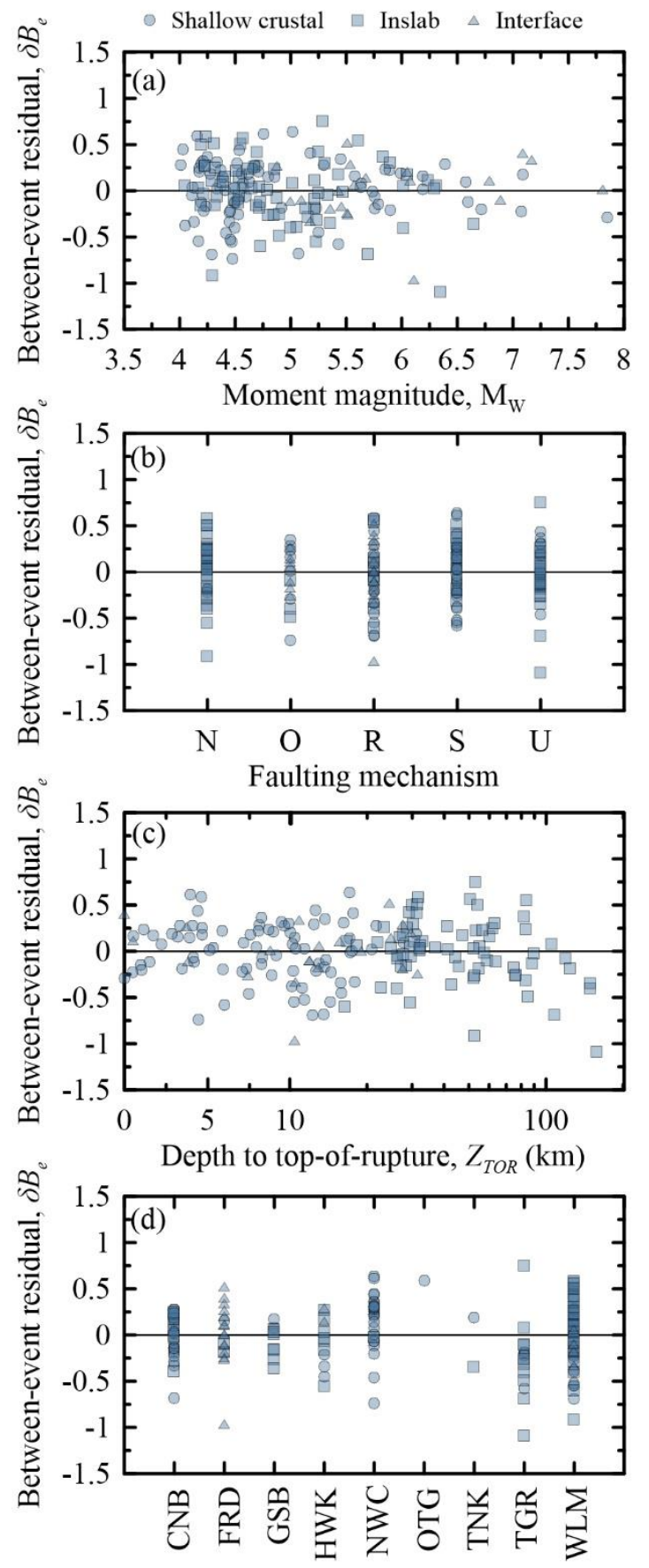

Region

Figure 6: Between-event residuals for CAV versus (a) moment magnitude, (b) faulting mechanism, (c) depth to topof-rupture, and (d) region. 

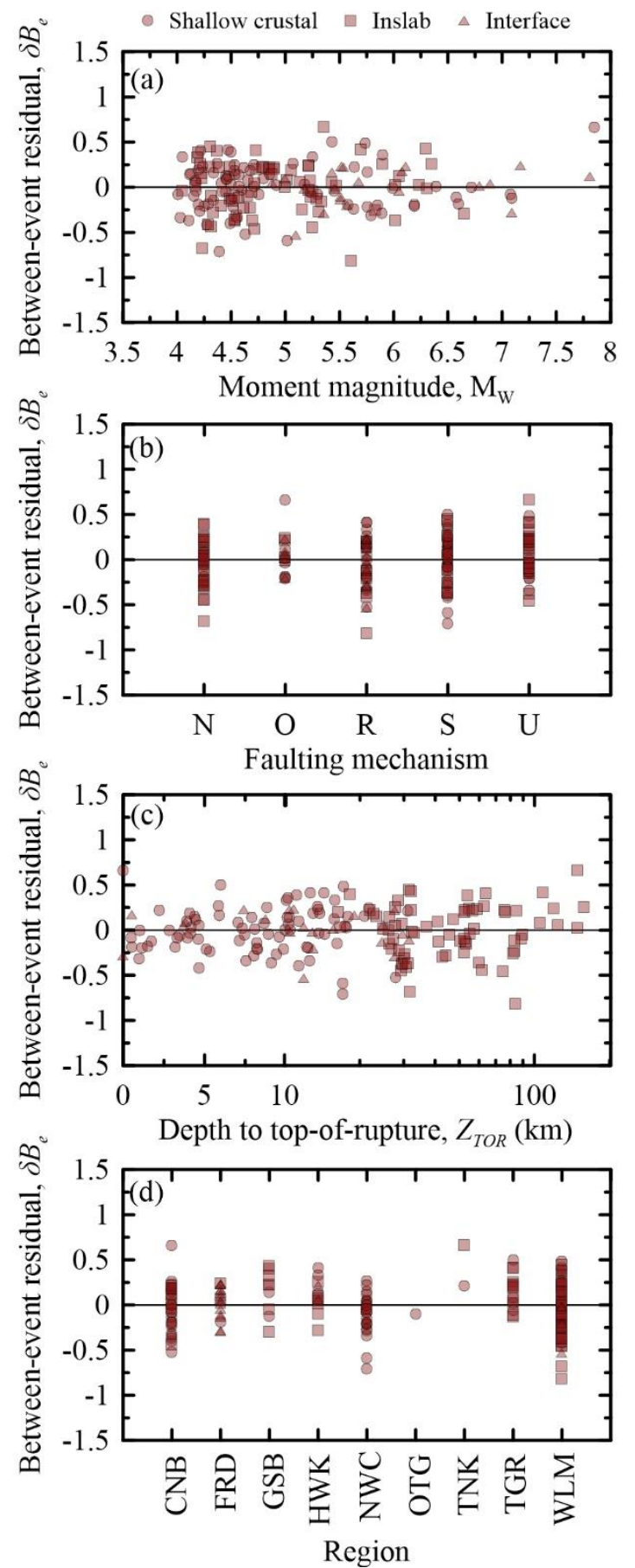

Figure 7: Between-event residuals for $D_{5-75}$ versus (a) moment magnitude, (b) faulting mechanism, (c) depth to topof-rupture, and (d) region.

Figures 8 and 9 show the within-event residuals $\left(\delta W_{e s}\right)$ as a function of the path and site parameters in the functional form $\left(R_{J B}, V_{S, 30}\right.$, and $\left.Z_{1.0}\right)$ for $C A V$ and $D_{5-75}$. No bias is evident on any parameter. The within-event residuals also pass Lilliefors [44] normality tests in all cases.

Previous research has highlighted the need to examine the attenuation of deep inslab earthquakes on the North Island [45]. Such earthquakes may produce stronger shaking at longer distances, depending on their depth and the location of their epicentres. None of the terms in Equation 12 directly model these effects, although they may be captured by the existing terms. Figure 10 shows the within-event residuals for the slab model as functions of additional distance measures not included in the functional form $\left(R_{\text {hypo }}, R_{\text {epi }}\right.$, and $\left.R_{x}\right)$, as well as $R_{T V Z}$. The only distance measure that shows any bias is $R_{\text {hypo }}$, which may show systematic under-prediction for the records with the smallest values. This feature is only evident for a handful of records, and more data are needed to verify whether this is a bias in the model or rather a lack of data.
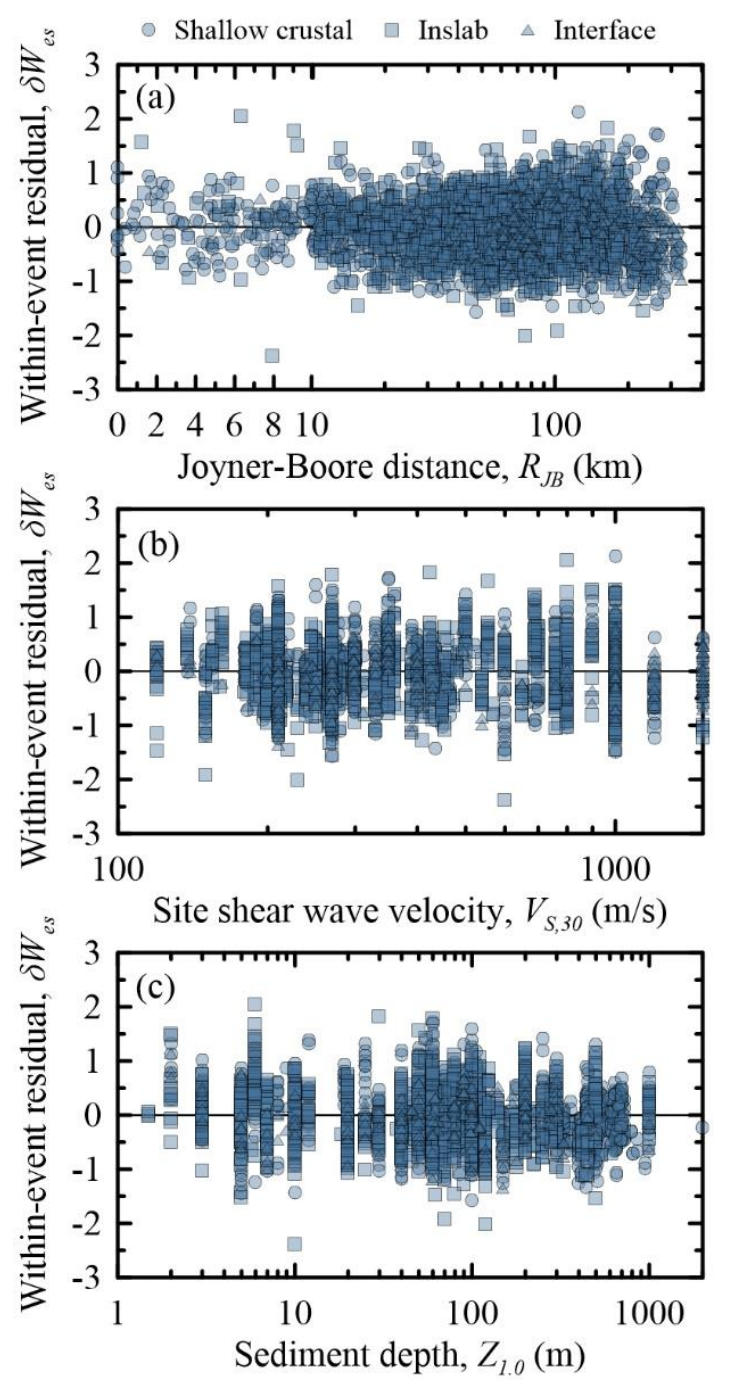

Figure 8: Within-event residuals for CAV versus (a) JoynerBoore distance, (b) site shear wave velocity, and (c) sediment depth.

\section{Uncertainty}

Homoscedastic values of the between- and within-event standard deviations $(\tau$ and $\varphi)$ are provided in Table 13 . Equation 12 defines the total uncertainty around the median predictions $(\sigma)$.

$$
\sigma=\sqrt{\tau^{2}+\varphi^{2}}
$$

Figures 6 through 9 show that the between- and within-event standard deviations are not heteroscedastic with any input parameter, with the possible exceptions of $R_{J B}$, which may have relatively smaller uncertainty for near-source motions, and $M_{W}$, which may have relatively smaller uncertainty for large magnitude events. However, because there are relatively fewer records in the database for very short $R_{J B}$ and large $M_{W}$, using narrower uncertainty may not be applicable for forward analysis. 

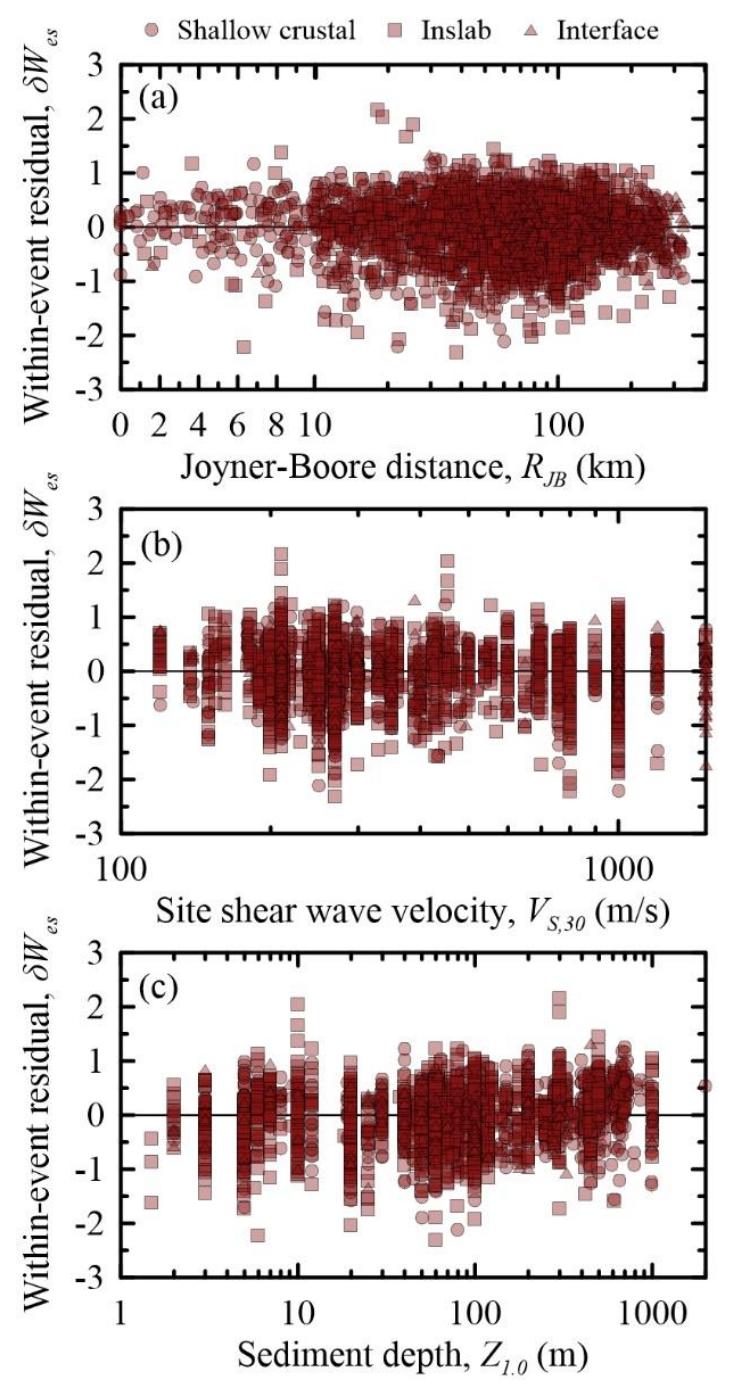

Figure 9: Within-event residuals for $D_{5-75}$ versus (a) JoynerBoore distance, and (b) site shear wave velocity.

The shallow crustal and inslab models have very similar values of $\tau$ and $\varphi$, but the interface model generally has smaller values of both standard deviations for all IMs. The apparently smaller uncertainty in the interface model is likely the result of its database size rather than any real difference in the variability of shaking compared to shallow crustal and inslab events. Applying an adjustment to account for epistemic uncertainty is especially necessary for the interface model. No New Zealandspecific recommendations for epistemic uncertainty have been made, much less for the IMs considered here, and producing such a set of recommendations (e.g., Al Atik and Youngs [46] for the NGA models) remains a topic for future investigation. Regardless, epistemic uncertainty can be accounted for using the Bullock (2019) methodology, which replaces the formulated lognormal distributions with log-logistic distributions.

\section{Spatial Correlation}

\section{Isotropic Spatial Correlations}

First, empirical semivariograms are calculated for the $\delta W_{e s}$ of each earthquake and models are fit using the Gaussian functional form (shown in Equation 13), where $\gamma$ is the semivariance, $h$ is the separation distance of the two considered locations, and $\ell$ is the correlation distance. The semivariograms are calculated using a maximum separation distance of $200 \mathrm{~km}$ and 20 bins.
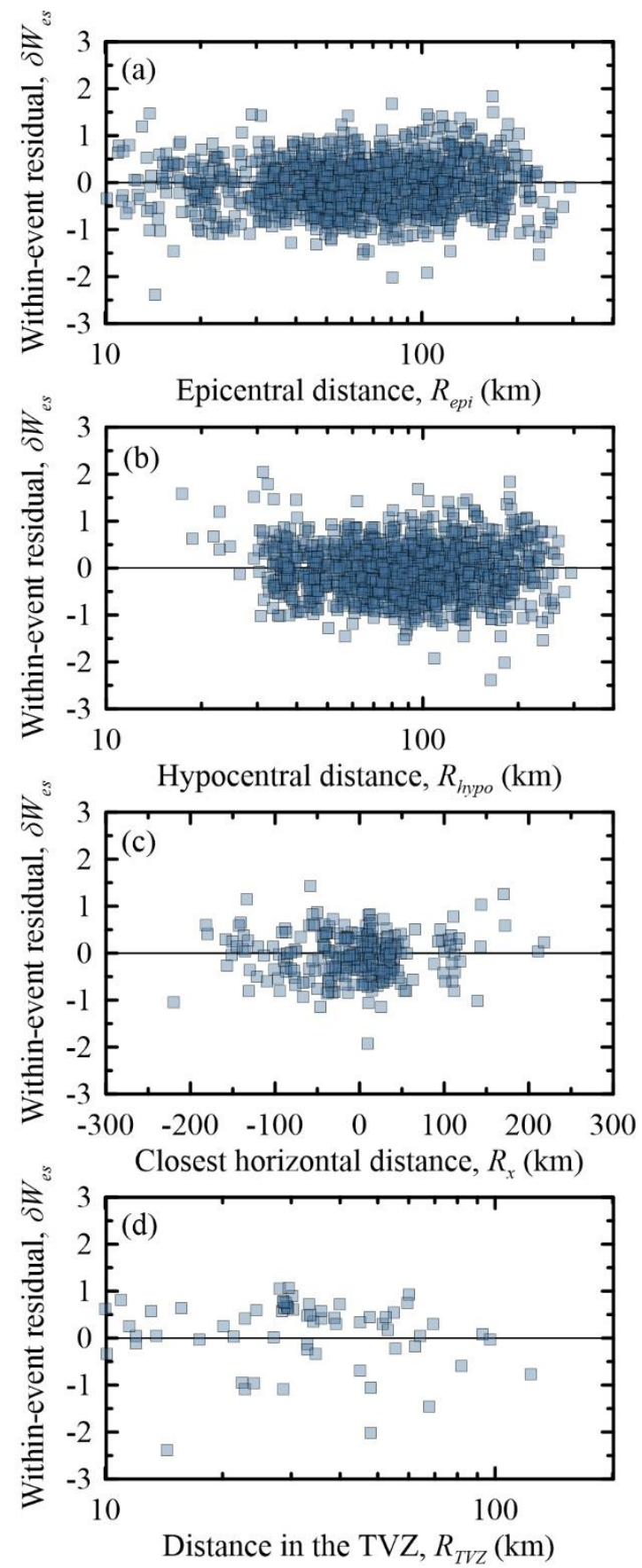

Figure 10: Within-event residuals for CAV versus (a) epicentral distance, (b) hypocentral distance, (c) closest horizontal distance, and (d) distance in the TVZ.

$$
\gamma(h)=1-\exp \left(-3 \frac{h^{2}}{\ell^{2}}\right)
$$

Note that the correlation coefficient $(\rho)$ between the $\delta W_{e s}$ at the two locations is given by $\rho(h)=1-\gamma(h)$. The coefficient of 3 inside the exponential results in the correlation equalling approximately 0.05 at $h=\ell$ and allows us to interpret $\ell$ as the distance at which correlation becomes negligible.

As in Foulser-Piggott and Stafford [38], this study finds that $\ell$ is highly variable from earthquake to earthquake and does not appear to display any trends with any source parameters, complicating its use for forward analysis. The $R^{2}$ values of the fitted Gaussian functions range between 0.02 and 0.99 with a median of 0.71 . The correlation lengths calculated in this study are too large to be useful for forward analysis in many cases. Table 16 reports the $15^{\text {th }}, 50^{\text {th }}$, and $85^{\text {th }}$ percentiles of $\ell\left(\ell_{15}\right.$, $\ell_{50}$, and $\ell_{85}$, respectively) across all tectonic classes and IMs. 
These summary statistics are provided to communicate the dispersion and skewness of the per-earthquake values of $\ell$.

No consistent trends relating source parameters, $\delta B_{e}$, the $R^{2}$ of these Gaussian functions, and the calculated isotropic $\ell$ could be identified. Therefore the confidence in the estimated $\ell$ values is generally low, particularly given their size, which is large compared to values obtained in previous studies (e.g., [47]).

Table 16: Regional distribution of events and records in the database.

\begin{tabular}{lccc}
\hline \multicolumn{1}{c}{ Direction } & $\begin{array}{c}\boldsymbol{\ell}_{\mathbf{1 5}} \\
(\mathbf{k m})\end{array}$ & $\begin{array}{c}\boldsymbol{\ell}_{\mathbf{5 0}} \\
(\mathbf{k m})\end{array}$ & $\begin{array}{c}\boldsymbol{\ell}_{\mathbf{8 5}} \\
(\mathbf{k m})\end{array}$ \\
\hline Isotropic & 9 & 35 & 89 \\
\hline Strike-parallel & 11 & 39 & 124 \\
\hline Strike-perpendicular & 6 & 11 & 71 \\
\hline
\end{tabular}

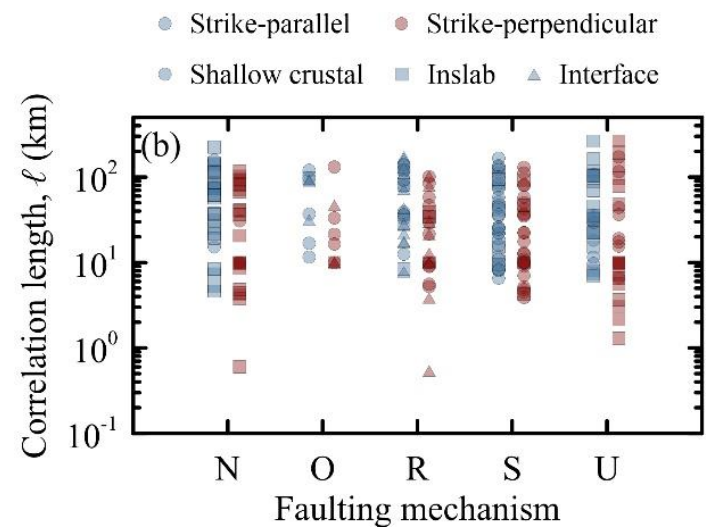

Figure 11: Strike-parallel and strike-perpendicular anisotropic correlation lengths for each faulting mechanism and tectonic class for RotD50 CAV.

\section{Anisotropic Spatial Correlation}

In an attempt to refine the isotropic spatial correlation model, anisotropy is introduced. The anisotropy is introduced such that the strike-parallel and strike-perpendicular separation distances between locations ( $h_{\text {para }}$ and $h_{\text {perp }}$, respectively) are used rather than the simple (i.e., isotropic) separation distance $(h)$. As for the isotropic case, the calculated values of the strikeparallel and strike-perpendicular correlation lengths are highly variable between earthquakes and are generally too large to reflect reality. The $R^{2}$ values for the fitted semivariograms range between 0 and 1 for both configurations, with medians of 0.44 for the strike-perpendicular case and 0.71 for the strikeparallel case.

The results show that spatial correlation is more strongly tied to the strike-parallel separation distance (i.e., higher $\ell_{15}, \ell_{50}$, and $\ell_{85}$ per Table 16), perhaps due to directivity effects (i.e., sites that are close together in the strike-parallel direction will be similarly affected by directivity if it is significant). Directivity effects are not considered in the median models developed here, and further research is needed to determine their effects on the IMs considered here and their spatial correlation. Figure 11 shows $\ell_{\text {para }}$ and $\ell_{\text {perp }}$ for each faulting mechanism and tectonic class. The difference between the two anisotropic correlation lengths is more pronounced for normal and reverse events, somewhat evident for strike-slip events, and not evident for oblique events. These differences may arise from the aforementioned directivity effects, but further investigation is required to confirm this hypothesis.

\section{MODEL TRENDS}

This section illustrates trends in the models and compares them to existing models from the literature. Figure 12 compares the RotD50 $I_{A}$ model developed here to Stafford et al. [11] for three well-recorded earthquakes: the 2010 Darfield earthquake, the 2011 Christchurch earthquake, the 2013 Lake Grassmere earthquake, and the 2016 Kaikōura earthquake. The average $V_{S, 30}$ of the records from these earthquakes is used to generate model predictions.
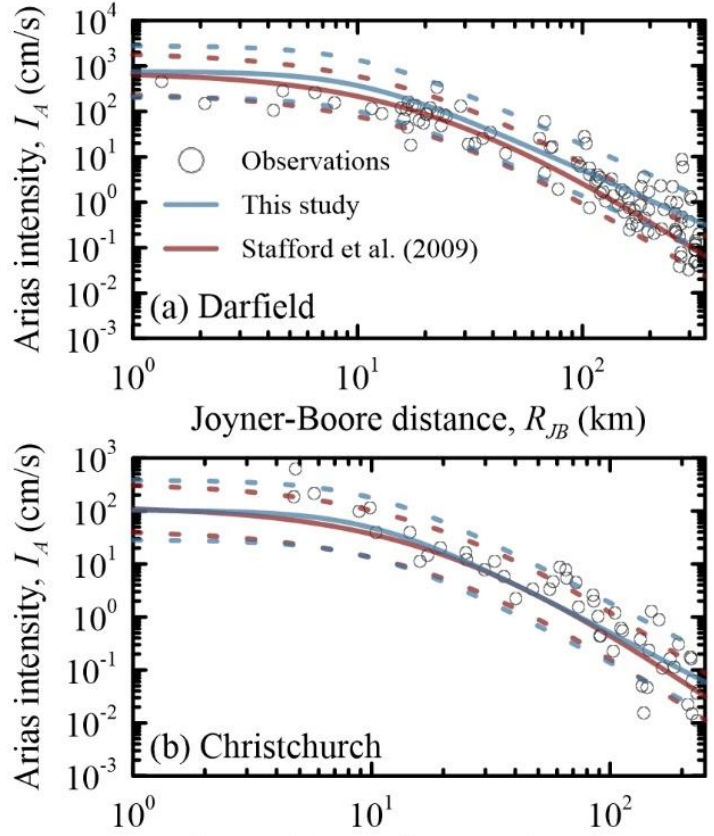

Joyner-Boore distance, $R_{J B}(\mathrm{~km})$

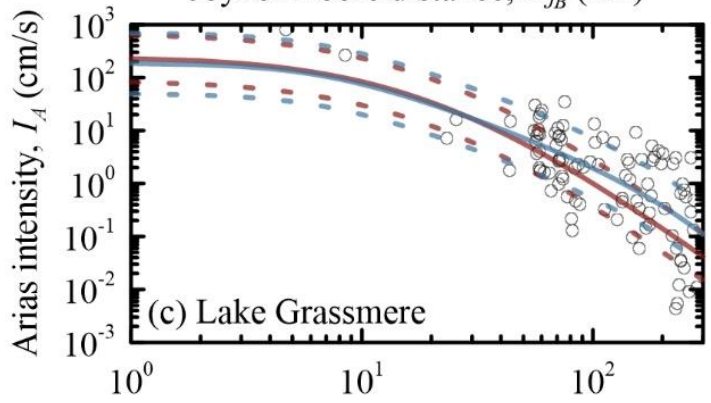

Joyner-Boore distance, $R_{J B}(\mathrm{~km})$

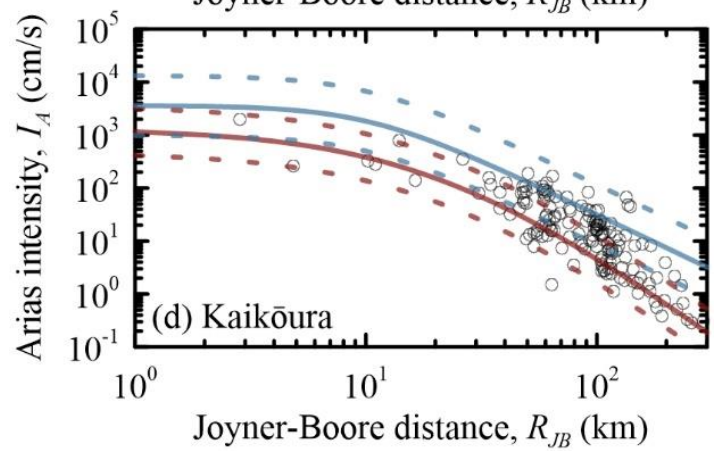

Figure 12: Comparison between this study (RotD50) and Stafford et al. [11] (geometric mean) for (a) the Darfield earthquake, (b) the Christchurch earthquake, and (c) the Lake Grassmere earthquake, and (d) the Kaiköura earthquake. 

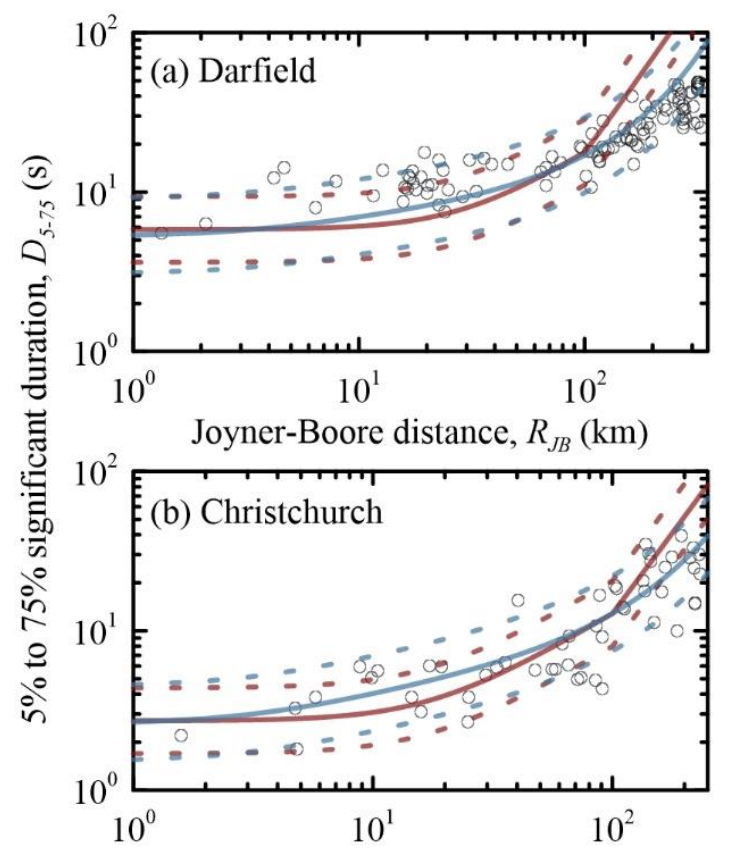

Joyner-Boore distance, $R_{J B}(\mathrm{~km})$
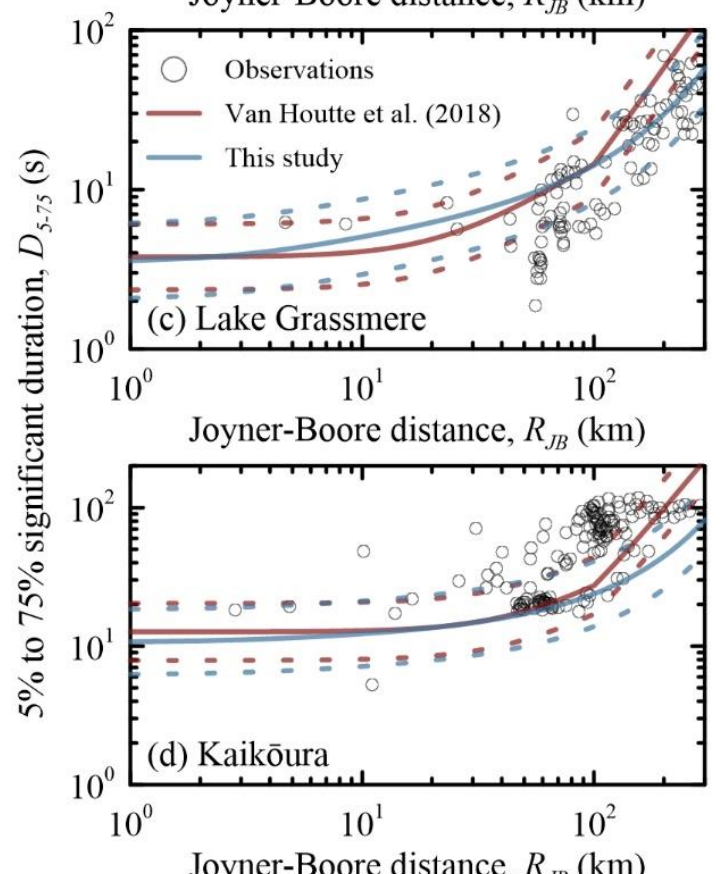

Figure 13: Comparison between this study and Van Houtte et al. [12] for (a) the Darfield earthquake, (b) the Christchurch earthquake, (c) the Lake Grassmere earthquake, and (d) the Kaikōura earthquake.

The model presented in this study tends to predict larger $I_{A}$ at short $R_{J B}$ (i.e., less than $15 \mathrm{~km}$ ) compared to Stafford et al. [11] in certain circumstances (i.e., for large magnitude crustal events), but smaller $I_{A}$ at short distances in other circumstances (i.e., for inslab events). The models agree closely at longer distances. The areas where these two models disagree have relatively fewer records available for regression.

Figure 13 shows a comparison between this study and the Van Houtte et al. [12] model for $D_{5-75}$ for the same four earthquakes. The two models show good agreement for short to medium $R_{J B}$, except for larger magnitude crustal events (i.e., the Darfield earthquake). This study predicts shorter significant durations for long $R_{J B}(>100 \mathrm{~km})$. Both models under-predict the significant duration of records from the Kaikōura earthquake, possibly due to its complex rupture pattern (e.g., [48-49]). This under-prediction is more severe for the models developed in this study.

Figure 14 compares the magnitude scaling in this study with that of Stafford et al. [11] and Van Houtte et al. [12]. Recall that both of these models (and this study) are specifically intended for use in New Zealand. This study predicts larger $I_{A}$ than Stafford et al. [11] and shorter durations than Van Houtte et al. [12] for large magnitude events. These differences are more pronounced at shorter distances. The model developed in this study has a negative gradient of significant duration versus magnitude for small magnitudes and large distances, but this trend is only observed for magnitude-distance combinations excluded by the filter given in Equation 5 .

Figures 15 and 16 compare the magnitude scaling and attenuation with distance in this study with that from the Bullock et al. [10] GMPEs for RotD100 $C A V$ and $V_{g i}$ on outcropping rock, respectively. The models generally agree but the models from this study predict larger $C A V$ and $V_{g i}$ for large magnitudes. The Bullock et al. [10] models are intended for use predicting outcropping rock intensity and therefore do not include site effects, whereas this model includes site effects as a function of both $V_{S, 30}$ and $Z_{1.0}$.
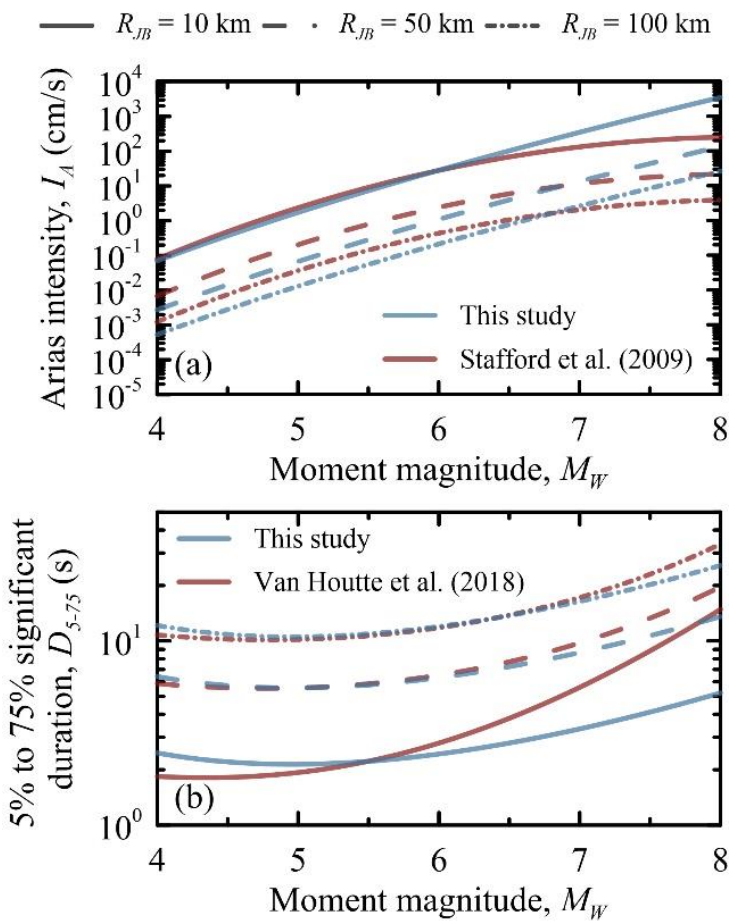

Figure 14: Comparison between (a) this study (RotD50) and Stafford et al. [11] (geometric mean) and (b) this study and Van Houtte et al. [12] as a function of magnitude for three Joyner-Boore distances $\left(V_{S, 30}=600 \mathrm{~m} / \mathrm{s}, Z_{1.0}=60 \mathrm{~m}\right.$ $Z_{T O R}=8 \mathrm{~km}, \mathrm{H}=12 \mathrm{~km}$, for a strike-slip shallow crustal event). 


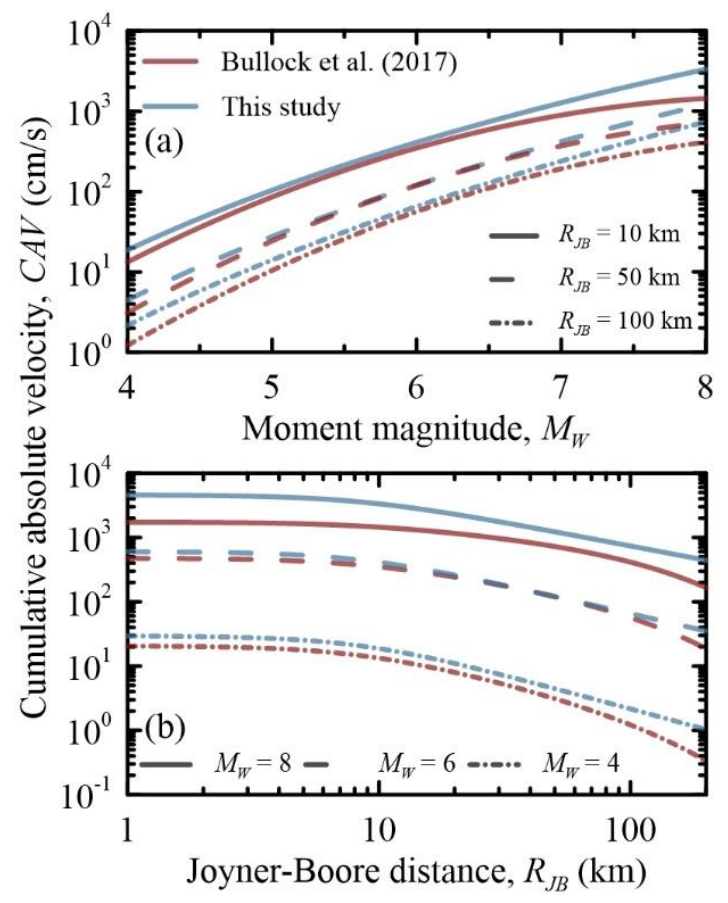

Figure 15: Comparison between this study (RotD100) and Bullock et al. [10] (RotD100) as (a) a function of magnitude for three Joyner-Boore distances and (b) a function of Joyner-Boore distance for three magnitudes $\left(V_{S, 30}=\right.$ $1100 \mathrm{~m} / \mathrm{s}, Z_{1.0}=0 \mathrm{~m} Z_{T O R}=8 \mathrm{~km}, \mathrm{H}=12 \mathrm{~km}$, for $a$ strike-slip shallow crustal event) for cumulative absolute velocity.

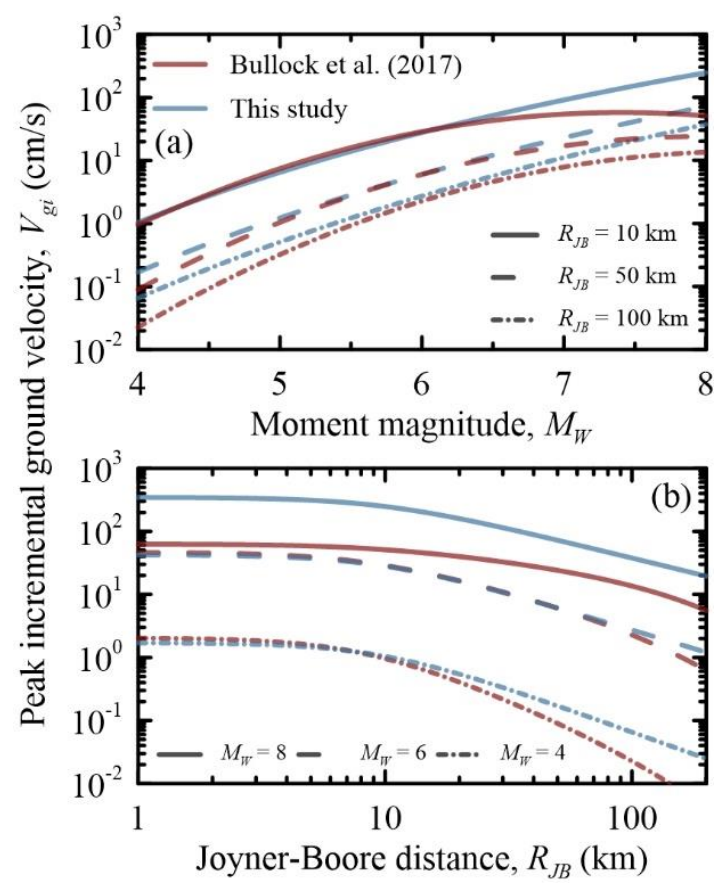

Figure 16: Comparison between this study (RotD100) and Bullock et al. [10] (RotD100) as (a) a function of magnitude for three Joyner-Boore distances and (b) a function of Joyner-Boore distance for three magnitudes $\left(V_{S, 30}=\right.$ $1100 \mathrm{~m} / \mathrm{s}, Z_{1.0}=0 \mathrm{~m} Z_{T O R}=8 \mathrm{~km}, H=12 \mathrm{~km}$, for $a$ strike-slip shallow crustal event for peak incremental ground velocity).

\section{CONCLUDING REMARKS}

This study presents empirical ground motion models for a handful of non-spectral intensity measures and significant durations for earthquakes in New Zealand. Models for the probability that the IMs take on nonzero values are also developed for the relevant IMs. Finally, spatial autocorrelation of the model within-event residuals is also considered. As in [8], the spatial autocorrelation is found to be highly variable from event to event and is therefore not useful for forward analysis.

The New Zealand Strong Motion Database provides the data used to regress the models. Arias intensity, two variations of cumulative absolute velocity, peak incremental ground velocity, and the 5\%-75\% and 5\%-95\% significant durations are included. The uncertainty around the proposed models is comparable to that of other models in the literature for these IMs [7-11], and their predictions compare favourably to those in the literature for prediction of non-spectral IMs and significant durations for earthquakes in New Zealand. The models are applicable for the following ranges of input parameters:

- $4 \leq M_{W} \leq 8$

- $\quad 0 \leq Z_{T O R} \leq 150 \mathrm{~km}$

- $0 \leq R_{J B} \leq 350 \mathrm{~km}$

- $100 \leq V_{S, 30} \leq 1,600 \mathrm{~m} / \mathrm{s}$

- $0 \leq Z_{1.0} \leq 1,000 \mathrm{~m}$

\section{REFERENCES}

1 Cornell CA (1968). "Engineering seismic risk analysis". Bulletin of the Seismological Society of America, 58(5): 1583-1606.

2 Abrahamson NA, Silva WJ and Kamai R (2013). "Update of the ASO8 ground-motion prediction equations based on the NGA-West 2 data set". Pacific Earthquake Engineering Research Center.

3 Atkinson GM and Boore DM (2003). "Empirical groundmotion relations for subduction-zone earthquakes and their application to Cascadia and other regions". Bulletin of the Seismological Society of America, 93(4), 1703-1729.

4 Boore DM, Stewart JP, Seyhan E and Atkinson GM (2014). "NGA-West2 equations for predicting PGA, PGV, and 5\% damped PSA for shallow crustal earthquakes". Earthquake Spectra, 30(3): 1057-1085.

5 Campbell KW and Bozorgnia Y (2014). "NGA-West2 ground motion model for the average horizontal components of PGA, PGV, and 5\% damped linear acceleration response spectra". Earthquake Spectra, 30(3): 1087-1115.

6 Chiou BSJ and Youngs RR (2014). "Update of the Chiou and Youngs NGA model for the average horizontal component of peak ground motion and response spectra". Earthquake Spectra, 30(3): 1117-1153.

7 Bommer JJ, Stafford PJ and Alarcón JE (2009). "Empirical equations for the prediction of the significant, bracketed, and uniform duration of earthquake ground motion". Bulletin of the Seismological Society of America, 99(6): 3217-3233.

8 Foulser-Piggott R and Goda K (2015). "Ground-motion prediction models for Arias intensity and cumulative absolute velocity for Japanese earthquakes considering single-station sigma and within-event spatial correlation". Bulletin of the Seismological Society of America, 105(4): 1903-1918.

9 Afshari K and Stewart JP (2016). "Physically parameterized prediction equations for significant duration 
in active crustal regions". Earthquake Spectra, 32(4): 2057 2081.

10 Bullock Z, Dashti S, Liel A, Porter K, Karimi Z and Bradley B (2017). "Ground-motion prediction equations for Arias intensity, cumulative absolute velocity, and peak incremental ground velocity for rock sites in different tectonic environments". Bulletin of the Seismological Society of America, 107(5): 2293-2309.

11 Stafford PJ, Berrill JB and Pettinga JR (2009). "New predictive equations for Arias intensity from crustal earthquakes in New Zealand". Journal of Seismology, 13(1): 31-52.

12 Van Houtte C, Larkin T and Holden C (2018). "On durations, peak factors, and non-stationarity corrections in Seismic Hazard Applications of Random Vibration Theory". Bulletin of the Seismological Society of America, 108(1): 418-436.

13 Van Houtte C, Bannister S, Holden C, Bourguignon S and McVerry G (2017). "The New Zealand strong motion database". Bulletin of the New Zealand Society for Earthquake Engineering, 50(1): 1-20.

14 Arias A (1970). "A measure of earthquake intensity" in Seismic Design for Nuclear Power Plants. The MIT Press, Cambridge, Massachusetts, 438-483.

15 Travasarou T, Bray JD and Abrahamson NA (2003). "Empirical attenuation relationship for Arias intensity". Earthquake Engineering and Structural Dynamics, 32(7): 1133-1155.

16 Electric Power Research Institute (1988). "A Criterion for Determining Exceedances of the Operating Basis Earthquake". EPRI Report NP-5930, Electric Power Research Institute, Palo Alto, CA.

17 Karimi Z and Dashti S (2017). "Ground motion intensity measures to evaluate II: the performance of shallowfounded structures on liquefiable ground". Earthquake Spectra, 33(1): 277-298.

18 Bullock Z, Karimi Z, Dashti S, Porter K, Liel AB and Franke KW (2018). "A Physics-Informed Semi-Empirical Probabilistic Model for the Settlement of Shallow-Founded Structures on Liquefiable Ground". Géotechnique, 69(5): 406-419.

19 Bullock Z, Dashti S, Karimi Z, Liel AB, Porter K and Franke KW (2019). "Probabilistic Models for Residual and Peak Transient Tilt of Mat-Founded Structures on Liquefiable Soils". ASCE Journal of Geotechnical and Geoenvironmental Engineering, 145(2): 04018108.

20 Bullock Z, Dashti S, Liel AB, Porter K and Karimi Z (2019). "Evaluation of Intensity Measures for Predicting Consequences of Soil Liquefaction on Shallow-Founded Structures”. Earthquake Spectra, 35(4): 1899-1926.

21 Kramer SL and Mitchell RA (2006). "Ground motion intensity measures for liquefaction hazard evaluation". Earthquake Spectra, 22(2): 413-438.

22 Electric Power Research Institute (2006). "Program on technology innovation: Use of cumulative absolute velocity $(C A V)$ in determining effects of small magnitude earthquakes on seismic hazard analyses". EPRI Report 1014099, EPRI, Palo Alto, CA, and the US Department of Energy, Germantown, MD.

23 Campbell KW and Bozorgnia Y (2011). "Prediction equations for the standardized version of cumulative absolute velocity as adapted for use in the shutdown of US nuclear power plants". Nuclear Engineering and Design, 241(7): 2558-2569.

24 Jampole E, Deierlein G, Miranda E, Fell B, Swensen S and Acevedo C (2016). "Full-Scale Dynamic Testing of a
Sliding Seismically Isolated Unibody House". Earthquake Spectra, 32(4): 2245-2270.

25 Bommer JJ and Martinez-Pereira A (1999). "The effective duration of earthquake strong motion". Journal of Earthquake Engineering, 3(02): 127-172.

26 Bommer JJ, Magenes G, Hancock J and Penazzo P (2004). "The influence of strong-motion duration on the seismic response of masonry structures". Bulletin of Earthquake Engineering, 2(1): 1-26.

27 Raghunandan M and Liel AB (2013). "Effect of ground motion duration on earthquake-induced structural collapse". Structural Safety, 41: 119-133.

28 Chandramohan R, Baker JW and Deierlein GG (2016). "Quantifying the influence of ground motion duration on structural collapse capacity using spectrally equivalent records". Earthquake Spectra, 32(2): 927-950.

29 Rogan M (1982). “A geophysical study of the Taupo Volcanic Zone New Zealand". Journal of Geophysical Research: Solid Earth, 87(B5): 4073-4088.

30 Wilson CJN, Rogan AM, Smith IEM, Northey DJ, Nairn IA and Houghton BF (1984). "Caldera volcanoes of the Taupo Volcanic Zone, New Zealand". Journal of Geophysical Research: Solid Earth, 89(B10): 8463-8484.

31 Cole JW (1990). "Structural control and origin of volcanism in the Taupo Volcanic Zone, New Zealand." Bulletin of Volcanology, 52(6): 445-459.

32 McVerry GH, Zhao JX, Abrahamson NA and Somerville PG (2006). "Crustal and subduction zone attenuation relations for New Zealand earthquakes". Bulletin of the New Zealand Society for Earthquake Engineering, 39(1).

33 Bradley BA (2013). “A New Zealand-specific pseudospectral acceleration ground-motion prediction equation for active shallow crustal earthquakes based on foreign models". Bulletin of the Seismological Society of America, 103(3): 1801-1822.

34 Cousins WJ, Zhao JX and Perrin ND (1999). "A model for the attenuation of peak ground acceleration in New Zealand earthquakes based on seismograph and accelerograph data". Bulletin of the New Zealand National Society for Earthquake Engineering, 32(4): 193-220.

35 Pinheiro J, Bates D, DebRoy S and Sarkar D (2014). "Linear and nonlinear mixed effects models". $R$ package, version 3.

36 Stafford PJ (2014). "Crossed and nested mixed-effects approaches for enhanced model development and removal of the ergodic assumption in empirical ground-motion models". Bulletin of the Seismological Society of America, 104(2): 702-719.

37 Stafford PJ (2008). "Conditional prediction of absolute durations". Bulletin of the Seismological Society of America, 98(3): 1588-1594.

38 Foulser-Piggott R and Stafford PJ (2012). “A predictive model for Arias intensity at multiple sites and consideration of spatial correlations". Earthquake Engineering and Structural Dynamics, 41(3): 431-451.

39 Cressie N and Huang HC (1999). "Classes of nonseparable, spatio-temporal stationary covariance functions". Journal of the American Statistical Association, 94(448): 13301339.

40 Cressie N (1985). "Fitting variogram models by weighted least squares". Journal of the International Association for Mathematical Geology, 17(5): 563-586.

41 Mooney HM (1970). "Upper mantle inhomogeneity beneath New Zealand: seismic evidence". Journal of Geophysical Research, 75(2): 285-309. 
42 Haines AJ (1981). "A local magnitude scale for New Zealand earthquakes". Bulletin of the Seismological Society of America, 71(1): 275-294.

43 Arlot S and Celisse A (2010). "A survey of cross-validation procedures for model selection". Statistics Surveys, 4: 4079.

44 Lilliefors HW (1967). "On the Kolmogorov-Smirnov test for normality with mean and variance unknown". Journal of the American Statistical Association, 62(318): 399-402.

45 Eberhart-Phillips D and McVerry G (2003). "Estimating slab earthquake response spectra from a 3D Q model". Bulletin of the Seismological Society of America, 93(6): 2649-2663.

46 Atik LA and Youngs RR (2014). "Epistemic uncertainty for NGA-West2 models". Earthquake Spectra, 30(3): 13011318.
47 Jayaram N and Baker JW (2009). "Correlation model for spatially distributed ground-motion intensities". Earthquake Engineering and Structural Dynamics, 38(15): 1687-1708.

48 Cesca S, Zhang Y, Mouslopoulou V, Wang R, Saul J, Savage M, Heimann S, Kufner SK, Oncken O and Dahm T (2017). "Complex rupture process of the Mw 7.8, 2016, Kaikoura earthquake, New Zealand, and its aftershock sequence". Earth and Planetary Science Letters, 478: 110120.

49 Zhang H, Koper KD, Pankow K and Ge Z (2017). "Imaging the $2016 \mathrm{Mw}$ 7.8 Kaikoura, New Zealand, earthquake with teleseismic P waves: A cascading rupture across multiple faults". Geophysical Research Letters, 44(10): 4790-4798. 